No. 21-16

\title{
Optimal Allocation of Relief Funds: The Case of the Paycheck Protection Program
}

\author{
Gustavo Joaquim and Felipe Netto
}

\begin{abstract}
:
The Paycheck Protection Program (PPP) was a large and unprecedented small-business support program that allocated $\$ 800$ billion in loans and grants to small businesses following the onset of the COVID-19 crisis. This paper explores the optimal allocation of funds across firms and the distortions caused by allocating these funds through banks. We show that it can be optimal to allocate funds to the least or most affected firms depending on the underlying distribution of the shock that firms face, the firms' financial position, and the total budget available for the program. In the model, as in the data, banks distort the allocation toward firms with more pre-pandemic debt and those less affected by the COVID-19 crisis. We characterize how this misallocation depends on the degree of asymmetric information between banks and the government. In an empirical application of our model, we estimate the PPP's effectiveness and compare it with alternative policies. A policy targeted at the smallest firms could have increased the program's effectiveness significantly.
\end{abstract}

JEL Classifications: H81, G28, J21, E24

Keywords: Paycheck Protection Program, COVID-19, small-business lending, financial frictions

Gustavo Joaquim is an economist in the research department of the Federal Reserve Bank of Boston. His email address is Gustavo.Joaquim@bos.frb.org. Felipe Netto is an economics PhD candidate at Columbia University. His email address is $\underline{\mathrm{fd} 2382 @ \text { columbia.edu. }}$

The authors thank Falk Bräuning, Jose Fillat, Joe Peek, Joanna Stavins, Adi Sunderam, Christina Wang, Paul Willen, Eric Zwick, Andrei Zlate (discussant), and participants of the Fama-French/Journal of Finance Conference on the Financial Consequences of the COVID-19 pandemic, the 37th International Conference of the French Finance Association, and the "How Is the COVID-19 Experience Changing Finance?" conference of the Center for Financial Innovation and Stability (CenFIS) for valuable comments and discussions. The authors also thank Morgan Klaeser for outstanding research assistance.

The views expressed herein are those of the authors and do not indicate concurrence by the Federal Reserve Bank of Boston, the principals of the Board of Governors, or the Federal Reserve System.

This paper, which may be revised, is available on the website of the Federal Reserve Bank of Boston at https://www.bostonfed.org/publications/research-department-working-paper.aspx. 


\section{INTRODUCTION}

The COVID-19 pandemic led to an unprecedented decrease in economic activity that affected small businesses in particular (Bartik et al. (2020a)). In April 2020, revenues of small businesses decreased more than 40 percent compared with January of the same year, and they were still down 20 percent in August (Chetty et al. (2020)). As a response, Congress created the novel Paycheck Protection Program (PPP) as part of the larger Coronavirus Aid, Relief, and Economic Security (CARES) Act. The main goal of the program was to preserve jobs of small and medium-sized businesses that were substantially affected by COVID-19. In 2020 and 2021, the total volume of loans and grants made through the program was $\$ 800$ billion. To speed up the delivery of loans to businesses, the government used financial institutions to make decisions on applications, but the loans were ultimately guaranteed by the government. ${ }^{1}$ This gave banks the ability to target loans to their preferred borrowers, particularly at the beginning of the program, when the demand for funds overwhelmingly exceeded the supply.

The empirical literature provides robust evidence of targeting of PPP loans. Granja et al. (2020), Bartik et al. (2020b), Doniger and Kay (2020), and Joaquim and Netto (2021) show that the earliest PPP loans were made to larger firms, firms with more preexisting debt, firms less affected by the pandemic, and firms that would have had a higher probability of survival without PPP loans. In this paper, we assess what should have been the optimal target of PPP loans, examine the distortions caused by allocating these loans through the banking system, and discuss alternative policies that could have been implemented to minimize the misallocation of PPP loans. Informed by our analysis of the PPP, we also highlight generalizable lessons for the design and evaluation of other interventions in credit markets.

Our theoretical framework has three agents: firms, banks, and the government. Each firm faces a random cost shock that must be paid for with its current cash-on-hand and potential borrowing from the PPP (as in Guerrieri et al. (2020)). Firms know the distribution, but not the realization, of this shock. ${ }^{2}$ Firms must choose to apply for the PPP and, conditional

\footnotetext{
${ }^{1}$ Throughout the paper, we refer to these intermediaries as banks for simplicity.

${ }^{2}$ This is a reasonable assumption, since the PPP was first introduced on March 27, 2020, long before the full magnitude of the pandemic was known. For example, a survey of small businesses in Bartik et al. (2020a) shows that there was substantial disagreement and uncertainty regarding the duration of the crisis.
} 
on applying, the total amount they apply for in the program, limited to a multiple of their total payroll. Consistent with the empirical evidence of Neilson, Humphries and Ulyssea (2020) and Bartik et al. (2020b), firms that are larger, more profitable, or more affected by the pandemic and firms with a higher treatment effect of receiving PPP loans are more likely to apply earlier.

We focus on the optimal allocation of a government that maximizes the number of preserved jobs, since the stated objective of the program was to "provide a direct incentive for small businesses to keep their workers on the payroll." ${ }^{3}$ We characterize the optimal allocation of PPP funds in two steps. First, we focus on the case where the government can choose how much to lend to each individual firm given the size of the program, which we denote as constrained first-best allocation. Second, we explore the case where the government must allocate loans to firms following the rules of the program, that is, only choosing which applications to approve.

In the constrained first-best case, the optimal allocation targets firms for which each additional dollar's marginal effect on the firm's survival probability is higher. For firms that face the same distribution of the cost shock, this implies the government finds that it is optimal to allocate money to firms with low cash-on-hand or high debt levels. On the other hand, when firms have similar financial conditions but face different cost shock distributions (due to different sectoral or regional exposure), the optimal allocation across firms depends on the size of the program. When the program is relatively small, the government finds it optimal to allocate funds in an inverted U-shaped pattern with respect to shock exposure; that is, firms moderately affected by the pandemic will be targeted first. Intuitively, allocating funds to the most affected firms is not cost effective (as those funds could be used alternatively to save even more firms that are only moderately affected). If, however, the program is sufficiently large, the government will prefer to allocate funds to the firms that are most affected. This analysis highlights that the target of the PPP is not ubiquitous: It depends on the nature of the shock faced by firms, how big the program is, and in which dimensions firms are heterogeneous.

When the government can choose only which applications to approve, it is optimal to

\footnotetext{
${ }^{3}$ See https://www.sba.gov/funding-programs/loans/covid-19-relief-options/paycheck-protectionprogram/first-draw-ppp-loan.
} 
allocate loans to firms with the greatest difference between their probabilities of survival with versus without a PPP loan, that is, the firms with the highest treatment effects. In our model, these firms are those that are moderately affected by the pandemic. Firms that are expected to be severely affected by the pandemic will likely shut down, while firms not significantly affected by the shock will likely survive-regardless of the allocation of PPP loans. Therefore, firms likely to be moderately affected by the cost shock have the highest treatment effects.

Given the optimal allocation of PPP loans from the perspective of the government, we study the potential misallocation from deploying these loans through banks. Banks have incentives that are different from the government's for two reasons. First, banks have outstanding loans with firms that will default if those firms do not survive the pandemic. As a result, banks distort the allocation toward firms to which they already have outstanding loans. Second, banks potentially lose clients if they reject their PPP applications and face uncertainty in the forgiveness process. ${ }^{4}$ As a result, banks distort the allocation toward less affected firms. Both of these effects are consistent with the empirical literature. For instance, Bartik et al. (2020b) show that approval rates are higher for less distressed firms and borrowers with larger outstanding debt. Together, these effects predict that the program will be systematically less effective than it would be if loans were allocated through the government.

Finally, we provide an empirical application of our model. First, using an empirical estimate of the effect of the PPP from Joaquim and Netto (2021), we quantify the misallocation of PPP loans. We find that the program was initially significantly less effective than it could have been under the optimal allocation, but this difference in effectiveness shrank as more loans were made. These results are a reflection of the excessive demand for PPP loans early in the program, when banks played a significant role in the allocation of PPP loans. Second, we explore a counterfactual in which the government allocates PPP loans. The government in this counterfactual has less information and operational capacity than banks, and as a consequence cannot optimally target firms and takes longer than banks to implement the program. We find that if the PPP program included "only" the $\$ 349$ billion appropriated in the CARES Act, it would have been better for the government to randomly assign loans across firms than

\footnotetext{
${ }^{4}$ This connects our theoretical results to empirical studies on the importance of bank relationships to the allocation decisions of banks, such as Li and Strahan (2020) and Amiram and Rabetti (2020).
} 
to allocate loans through banks. Additionally, we compute what the misallocation would have been if the government allocated loans to the smallest firms earlier and find that the program would have been significantly more effective. This would be a direct consequence of the smallest firms also being those with the highest treatment effects yet tended to receive loans later in program (Bartlett and Morse (2020)). Finally, we analyze the optimal size of the program. Increasing the size of the program to reduce the misallocation of loans would have been optimal only if the marginal cost of funds were low.

Our paper's analysis is key to understanding the economics behind not only the large and novel PPP, but also similar programs that have been implemented (for example, the Italian Guarantee Fund-see Core and De Marco (2021)) or that may be implemented in the future. According to Beck, Klapper and Mendoza (2010), loan guarantee programs are the most widely used type of government intervention in credit markets. Just as some policies were added to the toolkit of the government following the Great Financial Crisis (for example, liquidity facilities) and thus were quickly implemented in the COVID-19 crisis, programs such as the PPP will now be part of this toolkit. Our paper provides a framework for understanding which firms should be targeted by the government and under which conditions the program should be intermediated by the banking system versus directly operated by the government.

Related Literature. This paper joins the growing literature exploring the economic impact of policy responses to the COVID-19 pandemic, in particular the impact of the PPP. Autor et al. (2020) and Chetty et al. (2020) use the 500-employee eligibility cut-off to run a difference-in-differences analysis at the firm level. Neilson, Humphries and Ulyssea (2020) focus on the informational differences among small and large firms in terms of application and approval rates. Erel and Liebersohn (2020) shows that there is a significant level of substitutability between traditional banks and fintechs in the PPP. Chodorow-Reich et al. (2020) study differences in liquidity provision between small and larger firms, showing how the PPP ameliorated liquidity shortfalls experienced by small and medium-sized enterprises (SMEs), which have reduced access to credit lines relative to larger firms. Bartlett and Morse (2020) focuses on firm resiliency and labor flexibility.

Granja et al. (2020), Doniger and Kay (2020), and Joaquim and Netto (2021) provide evidence of regional targeting of PPP loans. Granja et al. (2020) and Doniger and Kay (2020) 
show that geographic regions receiving PPP loans earlier are those that were less affected by the pandemic. These regions saw a smaller decrease in small-business revenue, lower COVID-19 case counts, and higher mobility levels in early April 2020. Joaquim and Netto (2021) show that these results are also quantitatively important by controlling for bankcounty fixed effects, that is, by comparing the same county-bank pairs over time.

Bartik et al. (2020b) explore the early allocation of PPP loans using a survey of small businesses. Leveraging previous bank-firm relationships and heterogeneity in PPP processing at the bank level, Bartik et al. (2020b) show that applications from more distressed firms (for instance, those with less cash-on-hand) were less likely to be approved, despite large effects of the PPP on this set of firms. Moreover, banks favored firms with closer relationships to the bank rather than those in greater distress. A similar conclusion regarding lending relationships is reached by Li and Strahan (2020) and Amiram and Rabetti (2020), who investigate the connection between bank-firm relationships and access to PPP loans. ${ }^{5}$

Our contribution to this literature is twofold. First, the empirical literature on the PPP has so far focused on the observed allocation of PPP loans without - to the best of our knowledgeassessing the optimal allocation of loans and grants made through the program. For instance, while the key question in Granja et al. (2020) is, Did the PPP hit the target?; we ask, What should the PPP's target have been? Second, a lot of effort has been put into measuring the effect of the PPP, but less attention has been devoted to understanding what the effect of the PPP could have been if the program had been designed and implemented differently. We fill this gap by presenting a model that is consistent with the targeting evidence in the microdata and that allows us to quantify the misallocation of PPP loans and conduct counterfactuals.

Our paper also contributes to the literature on loan guarantee programs, which are a common form of intervention in credit markets (Beck, Klapper and Mendoza, 2010). These programs have been studied from a theoretical (Gale (1990); Gale (1991)) and empirical perspective (Lelarge, Sraer and Thesmar (2010); Mullins and Toro (2016); Brown and Earle (2017); de Blasio et al. (2018); Bachas, Kim and Yannelis (2020); Gonzalez-Uribe and Wang (2019); Julien and Vallée (2020)). We contribute to this literature by assessing the role of financial intermediaries and how to effectively design public policies aiming to protect employment

\footnotetext{
${ }^{5}$ Other PPP-focused studies include Hassan et al. (2020), Elenev, Landvoigt and Van Nieuwerburgh (2020), Faria-e Castro (2020), Cororaton and Rosen (2020), and Barrios et al. (2020).
} 
in downturns. This is particularly relevant given that there is a significant decrease of lifetime earnings following job displacement when the unemployment rate is high (Davis and Von Wachter, 2011).

\section{The Paycheck Protection Program}

In this section, we describe the Paycheck Protection Program (PPP). ${ }^{6}$ Created on March 27, 2020, as part of the Coronavirus Aid, Relief, and Economic Security (CARES) Act, the PPP was designed to address liquidity shortages that could lead to employment losses from small businesses. The Small Business Administration (SBA) oversaw the program. To guarantee a timely disbursement of funds, firms applied for a loan through qualified financial intermediaries.

Through 2020 and 2021, the PPP disbursed loans in two separate draws. The first draw ran from April 3 through August 8, 2020, and it is the one we consider in this paper. ${ }^{7}$ Given the PPP's small-business focus, only firms with fewer than 500 employees were eligible to apply, ${ }^{8}$ and each firm could apply for no more than one loan in the first draw of the program. The maximum loan amount was 2.5 times the firm's average monthly payroll costs in the preceding year, up to $\$ 10$ million. PPP loans have an interest rate of 1 percent, deferred payments for six months, and maturity of two years for loans issued before June 5, 2020, and five years for loans issued after that date. Moreover, PPP loans do not require collateral or personal guarantees.

A PPP loan is fully forgiven if funds are used for the specific purpose of payroll maintenance. Originally, to obtain full loan forgiveness, businesses were required to use at least 75 percent of the amount on payroll expenses and to maintain pre-crisis employment headcount and wage levels. This percentage was reduced to 60 percent after the Paycheck Protection Program Flexibility Act of 2020 was passed in June 2020. The amount forgiven is reduced if wages or full-time headcount decreases. Initially, funds had be used to pay for these costs

\footnotetext{
${ }^{6}$ This section is based on the analogous section in Joaquim and Netto (2021).

${ }^{7}$ In December 2020, Congress authorized an additional \$284 billion in funding for the program as part of the $\$ 900$ billion Coronavirus stimulus package. The PPP started making loans again in 2021, including seconddraw loans for some of the firms that had received a PPP loan in the first draw.

${ }^{8}$ The exceptions were firms in the restaurant and hospitality sectors (NAICS code 72), which were allowed to apply as long as they had no more than 500 employees in each location.
} 
over the eight-week period following the disbursement of the loan. This period was eventually extended to 24 weeks in June 2020.

Each application was processed by financial intermediaries, for example, federally insured depository institutions and credit unions, which were responsible for checking documentation submitted by applicants. For simplicity, we refer to these intermediaries as banks. Banks were paid a fee by the government to cover these processing costs. Importantly, loans from the PPP are fully guaranteed by the government and carry a zero risk weight for the calculation of risk-weighted assets, with the purpose of minimizing the impact on banks' capital requirements. Additionally, Federal Reserve Banks were authorized to provide liquidity to banks through the Paycheck Protection Program Lending Facility (PPPLF). This allowed Federal Reserve Banks to extend loans to institutions that were eligible to make PPP loans using such loans as collateral. Overall, the program was designed to allow a large number of institutions to process loan requests while minimizing the impact on their balance sheet structure.

Figure 1 shows the approval date of PPP loans through August 8, 2020, the application deadline of the first draw of the PPP. The first draw of the PPP was composed of two separate rounds. The first round of the program ran from April 3 to April 16, 2020. During the first round, PPP loan demand vastly exceeded supply. We see in Figure 2 that 72 percent of firms reported applying for the program, but only 36 percent reported receiving a PPP loan at the end of the first round. This excess loan demand gave banks a significant role in the allocation of PPP funds. Press accounts in the early days of the PPP show that banks gave preference to their existing clients and larger firms. ${ }^{9}$

As a consequence of the enormous demand for loans, the PPP ran out of money on April 16, 2020. In response, on April 24, Congress enacted the Paycheck Protection Program and Health Care Enhancement Act, which appropriated an additional \$321 billion (for a total of $\$ 670$ billion) for the PPP. The second round of the program ran from April 27 to August 8, 2020. In May 2020, two weeks after banks had resumed accepting applications, an additional $\$ 176$ billion in PPP loans was approved, and by May 15, 95 percent of the funds allocated in the program had already been dispersed. After that, demand for PPP loans subsided, and we

\footnotetext{
${ }^{9}$ See, for instance, Emily Flitter and Stacy Cowley, "Banks Gave Richest Clients Concierge Treatment for Pandemic Aid," New York Times, April 22, 2020, updated Oct. 11, 2021. https://www.nytimes.com/2020/04/22/business/sba-loans-ppp-coronavirus.html.
} 
saw excess supply of PPP loans, which reduced the role of banks in the allocation decision for PPP loans in the second round of the program. The program stopped accepting first-draw applications on August 8, 2020, with \$144 billion remaining from the Paycheck Protection Program and Health Care Enhancement Act appropriation.

Figure 1: Cumulative PPP Disbursement over Time (\$, Billions)

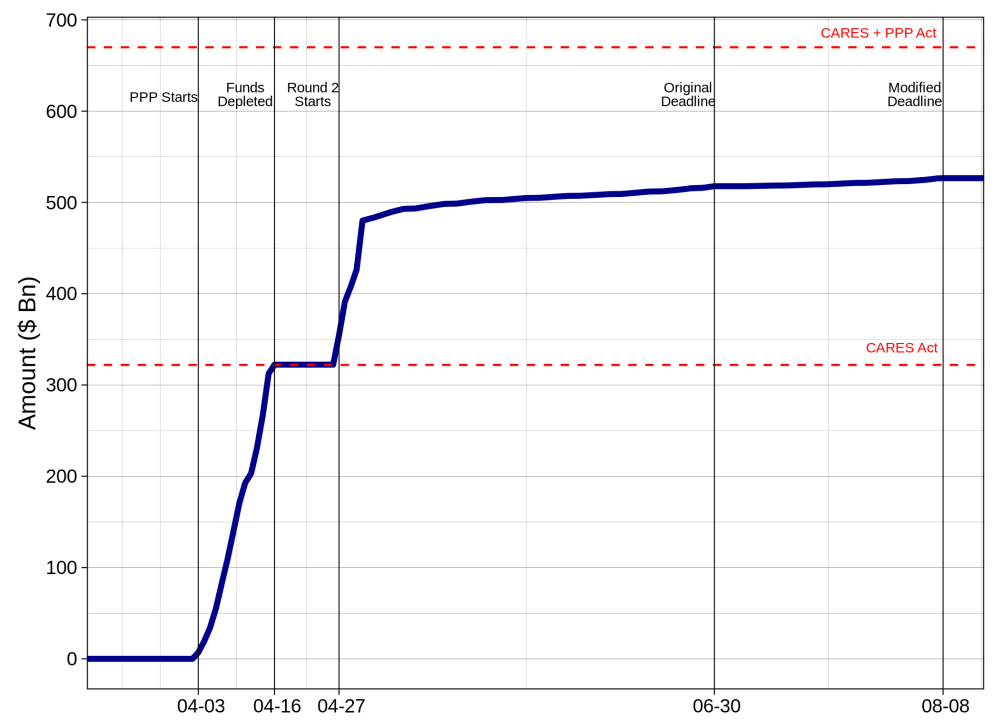

Note: Our primary source for data on the PPP comes from the SBA/Treasury release of loans made in the PPP (February 2021 version). The data set includes information self-reported by the borrower (name, address, Zip code, NAICS code and jobs supported) as well as loan amount, approval date, and lender name. We analyze the loans made in the first draw of the program (April 3 through August 8,2020). No loans were made in the program from August 8, 2020, through January 11, 2021 (when the second draw of PPP loans began). The date of a loan is the date of approval (according to the rules of the program, loans had to be disbursed within 10 calendar days of approval). Billions of dollars of PPP loans approved by day, from April 3, 2020, (CARES Act) through August 8, 2020 (modified deadline for second-round applications). Dashed horizontal lines represent the cumulative capacity of the program.

In Table 1, we report aggregate statistics of the first draw of the PPP. The program funded 5.147 million loans at a total value of $\$ 526$ billion. At the end of the first draw of the program, the (cumulative) average loan size was around $\$ 100,000$ for firms that self-reported, on average, 11.8 jobs supported by the program. Overall, firms reported more than 61.1 million jobs as being supported (in a universe of 70 million jobs at firms eligible for the program; see Autor et al. (2020)). Most of these loans were not made by the top four banks (in terms of 2019 assets). Together, these banks were responsible for around 36 percent of small-business loans (loan size less than \$ 1 million) before COVID-19, but they accounted for only $13 \%$ of the amount disbursed in the PPP. 
Figure 2: Small Business Pulse Survey: PPP Application vs. PPP Receipt (\% of Firms)

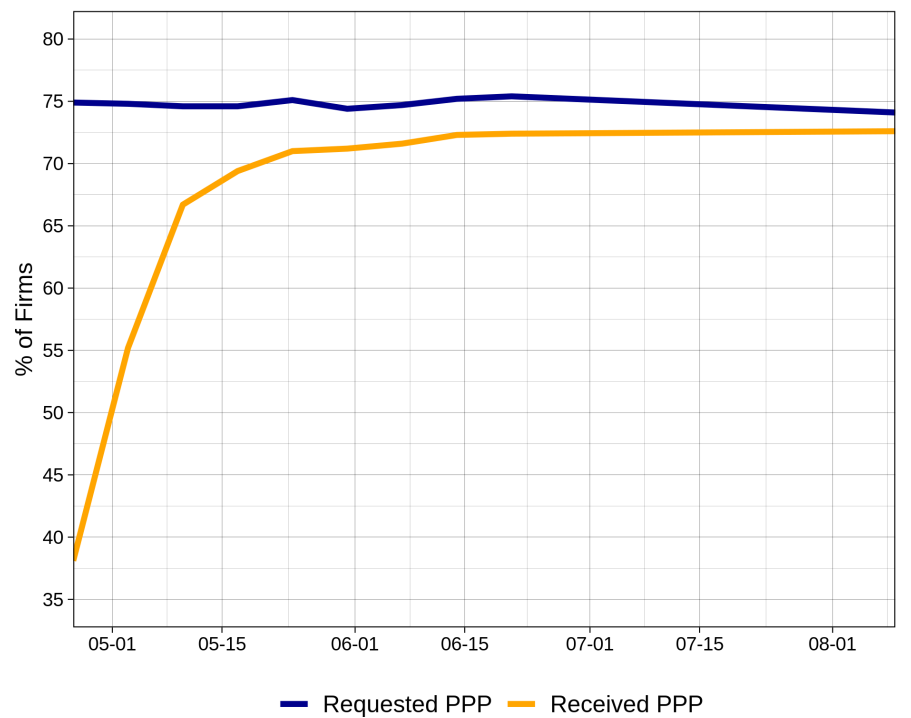

Note: US-level data from the Small Business Pulse Survey (SBPS) collected weekly from April 26 through June $21,2020)$. For details, see Buffington et al. (2020). The SBPS was designed to collect real-time information from small businesses during the pandemic. According to the Census, the target population is "all nonfarm, singlelocation employer businesses with 1 to 499 employees and receipts of \$1,000 or more." Data were collected weekly via email, from April 26 through June 21, 2020, based on the Census Bureau's Business Register. We use the state-sector (NAICS2) version of the data. The surveys are adjusted for non-responses and re-weighted weekly to guarantee representativeness. The blue line denotes the percentage of firms that reported applying for a PPP loan. The yellow line denotes the percentage of firms that reported receiving a PPP loan.

Table 1: Summary Statistics of the Paycheck Protection Program

\begin{tabular}{lccc}
\hline & Apr-16 & May-15 & Aug-08 \\
\hline Loan Amount (\$, Billions) & 322.2 & 498.4 & 526.6 \\
\# Loans (,000) & $1,619.7$ & $4,209.7$ & $5,147.6$ \\
Jobs Supported (Million) & 33.2 & 57.3 & 61.1 \\
Average Loan Size (\$,000) & 198.96 & 118.40 & 102.30 \\
Average Number of Employees & 20.5 & 13.6 & 11.8 \\
\hline Top-4 Share - \# Loans & 0.03 & 0.18 & 0.17 \\
Top-4 Share - Volume & 0.05 & 0.13 & 0.13 \\
\hline
\end{tabular}

Note: Data from the SBA/Treasury February 2021 release. Loan amounts (in billions of dollars) and number of loans (in thousands) cumulated after the start of the program (April 3, 2020). See Figure 1 for details. Average loan size is the ratio of the cumulative loan amount over the cumulative number of loans. Number of Employees was reported by the firms in the PPP application. The top four banks (by assets in December 2019) are (i) JP Morgan Chase, (ii) Bank of America, (iii) Wells Fargo, and (iv) Citibank, N.A.

\section{The Optimal Allocation of PPP Funds}

In this section, we describe the setting of our model, discuss the optimal allocation of a program's funds for the government and the potential misallocation from using the banking 
sector to disperse these funds. ${ }^{10}$

\section{III.1. Firms}

We consider a continuum of firms indexed by $j$. Each firm has $N_{j}$ workers. We define our model in terms of per worker variables. Firm j's cash-on-hand per worker before the onset of the pandemic and the launch of the lending program is given by Eq. (1)

$$
c_{j} \equiv \rho_{j}-b_{j}
$$

where $b_{j}$ represents the firm's debt payments per worker, and $\rho_{j}$ is the remainder of the cashon-hand. Without loss of generality, we normalize $N_{j}$ such that $\int_{j} N_{j} d j=1$. We assume that applying for the PPP has a fixed cost of $F$, and firms either choose to apply $\left(a_{j}=1\right)$ or not $\left(a_{j}=0\right)$ for the program. Each firm also chooses $\omega_{j}$, the amount per worker it applies for from the program, subject to a program limit based on the firm's current employment level $\varphi N_{j}$.

We model the pandemic following Guerrieri et al. (2020). Each firm faces a reduction $v_{j}$ in cash flow (revenue shortfalls, extra costs to remain open). The per-worker magnitude of the shock is $v_{j}$, with cumulative distribution denoted by $\Phi$ and probability distribution given by $\phi$, both parameterized by $\eta_{j}$ (we define the specific functional form for the distribution below). A firm that borrows $\omega_{j}$ from the lending program can survive the pandemic if

$$
v_{j}<c_{j}+\omega_{j} \equiv \Gamma_{j}\left(\omega_{j}\right)
$$

where $\Gamma_{j}(\omega)$ corresponds to the available funds per worker to guarantee firm survival. We assume that $\Gamma_{j}(0)>0, \forall j$; that is, all firms across all sectors and regions are profitable enough before the pandemic to remain open. ${ }^{11}$ A firm that borrows $\omega_{j}$ from the PPP wants to survive the pandemic if

$$
v_{j}<c_{j}-r_{G} \omega_{j}+\pi_{j}^{L R} \equiv \Pi_{j}\left(\omega_{j}\right)
$$

\footnotetext{
${ }^{10}$ The basic setting of our model is the same as in Joaquim and Netto (2021). The model we discuss here is more general and includes an analysis of the optimal allocation of PPP loans.

${ }^{11}$ As our focus is on the allocation of funds across firms, it is natural to assume that firms that are not profitable before the pandemic will shut down and won't receive any funds from the PPP.
} 
where $\pi_{j}^{L R}$ is the perpetuity value of long-run profits of the firm, and $\Pi_{j}$ is the total profit of the firm (both per worker). We assume that all firms that can survive want to survive-that is, $\Gamma_{j} \leq \Pi_{j}, \forall j .{ }^{12}$ Note that this assumption does not prevent the existence of zombie firms in our model. It is possible to have firms that are not profitable without PPP funds surviving due to the program. For example, consider that $\pi_{j}^{L R}=0$ and $r_{G}=-1$, such that $\Gamma_{j}=\Pi_{j}=c_{j}+\omega_{j}$. We can have a firm where $c_{j}<0$ and $c_{j}+\varphi>v_{j}$ as long as the program is sufficiently generous; that is, $\varphi>v_{j}-c_{j}$.

The problem of the firm is given by Eq. (2), where each firm chooses to apply or not apply for the program $\left(a_{j} \in\{0,1\}\right)$, and the amount to request from the program $(\omega \in[0, \varphi])$ is :

$$
\max _{a \in\{0,1\}, \omega \in[0, \varphi]} \int_{0}^{\Gamma_{j}(a \omega)} N_{j}\left[\Pi_{j}(a \omega)-v\right] d \Phi\left(v ; \eta_{j}\right) .
$$

In Eq. (2), we assume that the firm chooses $\omega_{j}$ before observing the realization of $v_{j}$, which is consistent with the fact that the firm does not know the extent of the pandemic or of its own exposure to it ex ante, but it knows the distribution of shocks it can face. This is a reasonable assumption given the uncertainty regarding the depth and duration of a pandemic. For instance, in a survey of more than 5,800 small businesses, Bartik et al. (2020a) show that there is substantial disagreement on the expected duration of the COVID-19 crisis across small businesses, and the reported levels of confidence in their expected duration is low. We assume in our benchmark model that banks and the government also observe $\eta_{j}$ (the parameter of the distribution) but not $v_{j}$ (the realization of the shock) in the main text. We solve the version where the government has imperfect information and a limited operational capacity to disburse loans in Section III.5.

For tractability, we follow Guerrieri et al. (2020) and assume that the cumulative distribution of the fixed-cost shock distribution is given by Eq. (3)

$$
\Phi(v ; \eta)=\left\{\begin{array}{l}
0, \text { if } v<0 \\
\left(\frac{v}{c_{0}}\right)^{\eta}, \text { if } v \leq c_{0} \quad, \text { with } \eta>0 . \\
1, \text { if } v>c_{0}
\end{array}\right.
$$

\footnotetext{
${ }^{12}$ Lending programs are designed as short-term sources of finance for these firms, such that it is expected that $\pi_{j}^{L R} \geq\left(1+r_{G}\right) \varphi$.
} 
The distribution in Eq. (3) has two characteristics that greatly simplify our analysis while still allowing us to focus on the difference between bank and government incentives. First, the shape parameter $\eta$ controls the concavity of the cumulative distribution function (CDF), and thus we have a monotonic probability density function (PDF), which is increasing if $\eta>1$ and decreasing if $\eta<1$. Second, a distribution with higher $\eta$ first-order stochastically dominates a distribution with lower $\eta$, making it easier to compare more affected (higher $\eta$ ) with least affected (lower $\eta$ ) firms.

For notation purposes, define $a_{j}^{*}, \omega_{j}^{*}$ as the solution to the problem in Eq. (4). Moreover, we simplify the notation by defining: $\Phi_{j}(\omega) \equiv \Phi\left(\Gamma_{j}(\omega) ; \eta_{j}\right)$, which is the probability a firm survives the pandemic if it receives $\omega$ from the program.

The objective function of the firm can be rewritten as Eq. (4). The expected profit is given by the probability of survival multiplied by the expected profit conditional on survival, subtracting the application cost (if the firm chooses to apply):

$$
\max _{\omega \in[0, \varphi], a \in\{0,1\}} \underbrace{\Phi_{j}(a \omega)}_{\text {Prob. Survival }} \cdot \underbrace{\left[\Pi_{j}(a \omega)-\mathbb{E}\left(v_{j} \mid v_{j} \leq \Gamma_{j}(a \omega)\right)\right]}_{\text {Expected Profit }}-a F .
$$

In Eq. (4), the problem of the firm is to balance borrowing to increase the probability of survival with reduced profitability in the future and the application cost. We can solve the problem in steps. First, consider a firm that has chosen to apply for the program. If the interest rate $r_{G}$ is too high, then the firm does not want to borrow from the program, as $\Pi_{i}^{L R}$ is decreasing and linear in $r_{G}$, and thus $\omega_{j}^{*}=0$. On the other hand, if $r_{G}<0$, as is the case with the PPP given the implicit grants in the program, then borrowing increases the probability of survival and increases profits in the future, thus, conditional on applying, $\omega_{i}^{*}=\varphi$.

Second, a firm applies for the program if the benefits of applying are larger than the fixed cost $F$. Firms with more workers $\left(N_{j}\right)$ apply more often given a smaller per-worker cost of applying. This is consistent with the survey evidence in Neilson, Humphries and Ulyssea (2020), who show that small businesses were less likely to be aware of, and apply for, the PPP program. To analyze the firm's benefits from the program, we introduce a key variable in our model. Let $T_{j}$ be the treatment effect for firms of type $j$ between receiving $\varphi$ or 0 loans from the PPP as in Eq. (5) 


$$
T_{j} \equiv \Phi_{j}(\varphi)-\Phi_{j}(0)
$$

The variable $T_{j}$ plays a special role, as it measures the expected effectiveness of the PPP program for each type of firm $j$. All else being equal, firm $j$ is more likely to apply for the program if $\left(c_{j}+\pi_{j}^{L R}\right) T_{j}$ is higher, that is, if the increase in expected profits is higher. However, this is not the only term that affects a firm's benefit from applying. Applying for the PPP increases the expected cost to be paid in terms of survival, that is, $\mathbb{E}\left(v_{j} \mid v_{j} \leq \Gamma_{j}(\varphi)\right)>$ $\mathbb{E}\left(v_{j} \mid v_{j} \leq \Gamma_{j}(0)\right)$, and the loan will have to be repaid at $r_{G}$. Putting it all together, firms that apply for the PPP are those that satisfy Eq. (6), which, using our specific distribution, can be written as Eq. (7). We define the set of all firms as $\mathcal{F}$ and the set of firms that apply as $\mathcal{A} \equiv\left\{j \mid a_{j}^{*}=1\right\}$. First, we will analyze the optimal allocation for the government outside the rules of the program across all firms, $\mathcal{F}$. Then, we will focus on the differences between the government and bank allocations under the rules of the program for firms that do apply, $\mathcal{A}$. All proofs and derivations are in the appendix.

Firm's Choice in the PPP. If $r_{G}<0$, then all firms apply for the maximum amount of PPP funds; that is, $\omega_{j}^{*}=\varphi$. Firms apply for the PPP $\left(a_{j}^{*}=1\right)$ if:

$$
T_{j} \Pi_{j}(0)-T_{j} \mathbb{E}\left[v_{j} \mid v_{j} \in\left[\Gamma_{j}(0), \Gamma_{j}(\varphi)\right]\right]-\Phi_{j}(\varphi) r_{G} \varphi>\frac{F}{N_{j}} .
$$

For the distribution in Eq. (7),

$$
\left[\frac{1}{\eta_{j}+1} c_{j}+\pi_{j}^{L R}\right] T_{j}-\Phi_{j}(\varphi)\left(\frac{\eta_{j}}{\eta_{j}+1}+r_{G}\right) \varphi>\frac{F}{N_{j}} .
$$

Dynamics and Timing of PPP Allocation. Our model of the PPP is a static model where we ask which firms should receive PPP funds. However, given the massive size of the program, a lot of the variation in PPP disbursements came from not only which firms received PPP loans, but also when those loans were received (see Doniger and Kay (2020), for instance). Most of our results can be easily extended for the timing of allocations. If we assume that neither firms' ability to survive nor treatment effects change over time, the problems are equivalent. More broadly, we can assume that firms' ability to survive and treatment effects change over 
time but do so proportionally for all firms, and our results of who should get PPP loans easily translate to who should get loans earlier in the program. Thus, we implicitly assume throughout our paper that if there is any time variation, it is of the form ${ }^{13}$

$$
\Phi_{j, t}(\varphi)=\alpha_{\Phi}(t) \Phi_{j}(\varphi) \text { and } T_{j, r}=\alpha_{T}(t) T_{j}
$$

and thus our results in terms of the allocation of PPP funds can be readily translated in terms of allocation timing. We come back to this discussion in our quantitative exercise in Section IV.

\section{III.2. Constrained First-Best Allocation}

Our first theoretical result is based on the problem of the government when it can choose the amount $\omega_{j}^{G}$ per worker to lend to each firm. The objective of the government is to maximize the number of preserved jobs. Since there is no intensive margin adjustment at the firm level (such as downsizing), we model this objective as maximizing the number of surviving jobs. The government observes the types of firms $j$ but not their actual realization of the pandemic shock, so we denote the solution of this problem as the constrained first-best, since the government is constrained by its information set.

We show that the government wants to allocate funds to where the marginal effect is the highest, which does not necessarily correspond to the places most/least affected by the shock. The marginal effect depends on the shock distribution, the size of the program, and the initial financial condition of the affected firms. The optimal target of the lending program thus is neither obvious nor invariant to the nature of the economic shock (as more information on the depth of the pandemic becomes available). For instance, if the shock for a firm (or region/sector) is large enough, the government does not always find it optimal to save this firm, as the opportunity cost of not allocating these funds to other firms is too high. Our analytical results below formalize this intuition and characterize what is then the government's optimal allocation.

Let the total amount of loans in the program be denoted by $M$. The problem of a planner

\footnotetext{
${ }^{13}$ For some of our results and our quantitative exercise, we could have a weaker assumption that time does not change the ordinal relation among the T's. We opt for the stronger assumption in our paper for simplicity.
} 
who aims to provide a direct incentive for small businesses to keep their workers employed is given by Eq. (9):

$$
\max _{\left\{\omega_{j}^{G}\right\}} \int N_{j} \cdot \Phi\left[\Gamma_{j}\left(\omega_{j}^{G}\right) \mid \eta_{j}\right] d j \text { s.t. } \int N_{j} \cdot \omega_{j}^{G} d j=M
$$

We denote the solution to the maximization problem in Eq. (9) by the constrained first-best (CFB). The constrained first-best solution is to allocate funds to where their marginal effect is higher, that is, where the marginal dollar will increase the probability of survival of firm $j$ the most.

In this section, we separately compare firms with the same shock exposure $\left(\eta_{j}\right)$ but heterogeneous financial position first, and then firms with the same financial position $\left(c_{j}\right)$ but different shock exposures. The motivation for this approach is twofold. First, it highlights the key channels of the PPP allocation in our model for different sources of heterogeneity across firms. Second, it speaks directly to the empirical literature that generally tries to control for either of these factors (with firm controls, fixed effects, etc.) and focus solely on one of them at a time (for instance, in Bartik et al. (2020b)). Our main analytical result of this section is Lemma 1 , which considers the case where $\eta_{j}<1, \forall j$, that is, where all firms face a concave distribution of the pandemic shock.

Lemma 1. Constrained first-best allocation with $\eta_{j}<1$. Let $\eta_{j}<1, \bar{c} \equiv \int_{j} N_{j} c_{j} d j>0$, and $c_{0}$ is sufficiently large. ${ }^{14}$ The solution to Eq. (9) entails an equal gain in the probability of survival across firms, that is, for firms $i, j$

$$
\phi\left[\Gamma\left(\omega_{j}^{G}\right)\right]=\phi\left[\Gamma\left(\omega_{i}^{G}\right)\right], \forall i, j
$$

Using the distribution in Eq. (3), we have that

$$
N_{j} \omega_{j}^{G, *}=N_{j} \tau\left(\eta_{j}, \bar{M}\right)+M-\left[N_{j} c_{j}-\bar{c}\right]
$$

where $\bar{M} \equiv M+\bar{c},{ }^{15}$ and $\tau(\eta, \bar{M})$ is an exposure-based per-worker transfer that sums to zero; that

\footnotetext{
${ }^{14}$ We assume that $c_{0}$ is sufficiently large to focus on the interior solution of the problem of the government. A sufficient condition for this interior solution is $c_{0}>M+\bar{\pi}$.

${ }^{15}$ This is the relative size of the program. $M$ represents the total funds to be allocated, and $\bar{c}$ represents the financial conditions of the firms at the onset of the shock.
} 
is, $\int_{j} N_{j} \tau\left(\eta_{j}, \bar{M}\right)=0$. Furthermore, we have that:

- $\bar{M}$ small- $\tau(\eta, \bar{M})$ is inverted U-shaped in $\eta \Rightarrow$ funds should flow to intermediately affected firms.

- $\bar{M}$ large- $\tau(\eta, \bar{M})$ is strictly increasing in $\eta \Rightarrow$ funds should flow to most affected firms.

Lemma 1 implies that for two firms $i, j$ with the same shock exposure $\eta_{j}=\eta_{i}$, we have that $N_{j} \omega_{j}^{G, *}-N_{i} \omega_{i}^{G, *}=N_{i} c_{i}-N_{j} c_{j}$, while for two firms with the same financial position $c_{j}=c_{i}$, we have that $N_{j} \omega_{j}^{G, *}-N_{i} \omega_{i}^{G, *}=N_{j} \tau\left(\eta_{j}, \bar{M}\right)-N_{i} \tau\left(\eta_{i}, \bar{M}\right)$. Intuitively, Lemma 1 shows that (i) the optimal policy maximizes the marginal probability of survival across firms (Eq. (10)), and (ii) this can be decomposed in the cash flow needs of firm $j$ relative to the average cash flow needs in the economy and a transfer based on the size of the program and exposure to the shock (Eq. (11)). Therefore, firms in a more fragile financial situation (as are small firms) would receive more funds from the PPP. Moreover, if the relative size of the program is large, the government can allocate enough funds to the most affected firms to significantly increase their probability of survival. On the other hand, if the program is relatively small, the government must focus on firms that are intermediately affected by the pandemic. Firms that are strongly affected would cost too much to save, if it were even possible to save them with a high probability, while the least affected firms could likely survive without PPP funds.

Sectoral/regional allocation. Our result in Lemma 1 is also useful for analyzing the optimal allocation of funds across different sectors and regions in the country, as there is evidence that the funds did not flow to the most affected regions (Granja et al. (2020)). The result that optimal policy will equate the marginal probability of survival across firms in Eq. (10) is still true for the marginal probability of survival across sectors and regions. For instance, if different sectors have different initial levels of debt per worker, sectors with relatively more debt per worker should receive more of the funds, since the probability that a firm in this sector survives the pandemic absent the government program is small, hence the marginal effect of funds on survival probability is large. However, if sectors or regions have shocks with different distributions (that is, different exposures to the pandemic), the optimal transfers across sectors are given by $\tau\left(\eta_{j}, \bar{M}\right)$ and shouldn't necessarily go to the most affected sectors or regions. 
Other cases. In Lemma 1, we focus on the case where $\eta_{j}<1, \forall j$. In Appendix C.1, we show in a simple example that when $\eta_{j}>1$, the problem of the government is convex and the solution is to allocate funds to either the firms with the lowest or highest $\pi$ or $\eta$; that is, the government is indifferent to the choice between allocating funds to the least or most affected firms as long as all of the funds flow to either. More generally, take any distribution $\Upsilon\left(\pi_{j}+\omega_{j} \mid \theta_{j}\right)$ parameterized by $\theta_{j}$. We show in Appendix C.2 that the government should allocate money to the highest $\theta_{j}$ (most affected) if $\Upsilon$ is supermodular in $\omega, \theta$ (and to the least affected if it is submodular). Overall, this shows that the optimal target of PPP funds depends on the benefit of the marginal dollar rather than the funding needs of each individual firm.

\section{III.3. Optimal Allocation of Loans under PPP Rules}

In Section III.2, we considered the government allocation when the government can choose how much to lend to each firm. To make a direct comparison with the bank allocation, we now focus on the optimal government allocation under the same rules as the bank allocation in the PPP, conditional on the set of firms that in fact apply for the PPP; that is, $j \in \mathcal{A}$. In this case, the government can choose to accept or reject applications from firms, but it cannot change the loan allocation at the intensive margin. This problem ensures that we are comparing the bank allocation with a government allocation equally constrained by the program (instead of the constrained first-best), and thus that any difference comes from banks incentives.

The problem of the government is to choose the probability $l_{j}^{G} \in[0,1]$ to accept the application from firm $j$, as in Eq. (12):

$$
\max _{\left\{l_{j}^{G} \in[0,1]\right\}} \int_{\mathcal{A}} N_{j}\left[l_{j}^{G} \Phi_{j}^{\Gamma}(\varphi)+\left(1-l_{j}^{G}\right) \Phi_{j}^{\Gamma}(0)\right] d j \text { s.t. } \int_{\mathcal{A}} N_{j} l_{j}^{G} d j=\frac{M}{\varphi}
$$

Distribution of firms/workers in the population. Note that so far we have used the shorthand notation of $d j$ to represent the integral over the distribution of firms, but we haven't defined how types of firms are present in the population. To provide clarity, we discuss what is implicitly behind this notation. Let $G(\rho, b, \eta, N)$ be the joint distribution of $\rho, b, \eta, N$ in the population of firms. For any variable at the firm level that is not a function of the number of 
employees, $x(\rho, b, \eta)$, we can write:

$$
\int N x(\rho, b, \eta) d G(\rho, b, \eta, N)=\int x(\rho, b, \eta) \bar{N}(\rho, b, \eta) d G(\rho, b, \eta)
$$

where $\bar{N}(\rho, b, \eta) \equiv \int_{N} N d G(N \mid \rho, b, \eta)$. The term $\bar{N}$ is the average number of employees of firms of a given type $\{\rho, b, \eta\}$, and it acts in our model as a shifter in the distribution of firms of type $\{\rho, b, \eta\}$. What matters in our model is not the marginal distribution of firms, but rather the marginal distribution of the firm variables at the job level. Thus, our model can encompass various other channels highlighted in the literature that focus on jobs and not firms. For instance, see the evidence in Bartlett and Morse (2020) of how firm survival varies by firm size.

As in our model, the treatment effect $T_{j}$ is not a function of $N_{j}$, and the resource constraint is linear in it. The optimal allocation $l_{j}^{G}$ is also not a function of $N_{j}$, where $d j$ in this case represents the integration of all firms of types $\left\{b_{j}, \rho_{j}, \eta_{j}\right\}_{j}$, with the cumulative distribution of type $j$ given by $G(\rho, b, \eta) \times \bar{N}(\rho, b, \eta)$. Following the argument in Eq. (13), we can write the problem of the government as Eq. (14)

$$
\max _{\left\{l_{j}^{G} \in[0,1]\right\}} \int_{\mathcal{A}} l_{j}^{G} T_{j} \text { dj s.t. } \int_{\mathcal{A}} l_{j}^{G} d j=\frac{M}{\varphi}
$$

where $d j$ in this case represents the integration of all firms of types $\left\{b_{j}, \rho_{j}, \eta_{j}\right\}_{j}$ with the cumulative distribution of type $j$ given by $G(\rho, b, \eta) \times \bar{N}(\rho, b, \eta)$, that is, the job-weighted distribution, as in Eq. (13). The exact same argument can be made for everything that follows in this paper, thus, in what follows, we leave the dependence on $N_{j}$ implicit.

From Eq. (14), it is clear that the government wants to approve the applications of firms with the highest treatment effect. The key question is, which firms are those in the case of the PPP? In the first result of Lemma 2, we show that for firms with the same $\eta$, the government wants to allocate loans to firms with high levels of debt $b_{j}$ (or low $\rho_{i}$ ) if $\eta<1$, and to firms with low levels of debt $b_{i}$ if $\eta>1$. If the shock is likely to be relatively small $(\eta<1)$, the government can try to save the firms that have the lowest probability of survival, which are those with high levels of debt per worker (ceteris paribus). On the other hand, for shocks that are most likely large, the government prefers simply to allocate the loans to firms with 
relatively low levels of debt, as those are the ones the government can still save in the face of the pandemic. The insight here is that the treatment effects are a joint product of firms' financial positions and the nature of the shock distribution, and thus they do not have a distribution or model-free ranking.

\section{Lemma 2. Government PPP allocation.}

Debt heterogeneity. Consider that all firms in the economy are equal except for their level of debt $b_{j}$; that is, $c_{j}=c>0$, and $\eta_{j}=\eta$. The solution to Eq. (14) implies that $\exists ! b^{*}$ such that: (i) for $\eta<1$, $l_{j}^{G}=1$ if $b_{j}>b^{*, G}$ and $l_{j}^{G}=0$ otherwise, and (ii) the opposite for $\eta>1 .{ }^{16}$

Shock exposure heterogeneity. Consider that all firms are equal except for their shock exposure $\eta_{j}$; that is, $c_{j}=c>0$. The solution to Eq. (14) implies that $\exists ! \underline{\eta}_{G}, \bar{\eta}_{G}$ such that the government chooses $l_{j}^{G}=1$ if $\eta_{j} \in\left[\underline{\eta}_{G}, \bar{\eta}_{G}\right]$ and $l_{j}^{G}=0$ otherwise.

In the second result of Lemma 2, we show that for firms with the same financial position $c_{j}$, the government wants to allocate loans to firms with intermediate exposure to the pandemic shock. This result involves the same intuition as the case where $M$ is small in the constrained first-best. The most affected firms won't survive with the extra $\varphi$, while the least affected firms will likely survive regardless, such that $\varphi$ is too much to allocate to them. Here, contrary to the constrained first-best, this is not a function of the total size of the program, $M$, since the amount at the intensive margin that the government can allocate to each firm is fixed. This second result of Lemma 2 is shown pictorially in Figure 3, where we compare the optimal allocation of the government with that of the private banking sector.

\section{III.4. Banks Optimal Allocation}

We now focus on the private banking sector allocation in the PPP. As in the government optimization problem Eq. (12), banks can choose to accept or reject applications from firms to maximize their profits. We focus on the problem of a single representative bank. For a model with multiple banks and bank heterogeneity, see Joaquim and Netto (2021).

Banks receive positive profits from making more loans and thus will make as many loans as possible in the program. If the bank accepts a PPP application, there are two possible

\footnotetext{
${ }^{16}$ Note that $b^{*, G}$ is different if $\eta$ is $<$ or $>$ than 1 . Moreover, for $l_{j}^{G}=b^{*, G}$, the government is indifferent regarding the allocation. As there is a continuum of firms, the allocation to this specific set of firms is irrelevant at the aggregate level.
} 
scenarios. If the firm survives, the bank recovers $b_{j}$ of the current loan payments and a present value of $\psi_{F} b_{j}$ from potential future loans to this firm. If the firm does not survive, the bank receives a share $\delta \in(0,1)$ of the current payments and no value from potential future loans to this firm. The same two scenarios are possible when the bank rejects the PPP application. However, we additionally assume that if the firm survives after having its application denied, there is a probability $\psi_{C}<1$ that the firm switches bank providers. ${ }^{17}$ Additionally, to incorporate potential uncertainty regarding loan guarantees, we assume that with probability $q$ the bank has to face the costs of the PPP loan, a concern for some banks in the pandemic. ${ }^{18}$

Let $l_{j, t}^{B} \in[0,1]$ be the choice of a bank to approve the application of a firm. The profit $\Pi_{j}^{B}$ per firm $j$ a bank receives is

$$
\begin{aligned}
\Pi_{j, t}^{B} \equiv & \left\{\Phi_{j, t}^{\Gamma}(\varphi)\left[1+\psi_{F}\right]+\left[1-\Phi_{j, t}^{\Gamma}(\varphi)\right]\left(\delta\left(1+\psi_{F}\right)-q \frac{\varphi}{b_{j}}\right)\right\} b_{j} l_{j}^{B}+ \\
& \left\{\Phi_{j, t}^{\Gamma}(0)\left[1+\left(1-\psi_{C}\right) \psi_{F}\right]+\left[1-\Phi_{j, t}^{\Gamma}(0)\right] \delta\left(1+\psi_{F}\right)\right\} b_{j}\left(1-l_{j}^{B}\right) \\
= & \Omega_{j, t}+\text { constant, }
\end{aligned}
$$

where

$$
\Omega_{j} \equiv T_{j}\left[(1-\delta) b_{j}+\psi_{F} b_{j}+q \varphi\right]+\theta_{j}\left[\psi_{C} \psi_{F} b_{j}+q \varphi\right]
$$

The problem of the bank is given by

$$
\max _{\left\{l_{j}^{B} \in[0,1]\right\}} \int_{\mathcal{A}} \Omega_{j} l_{j}^{B} d j \text { s.t. } \int_{\mathcal{A}} l_{j}^{B} d j=\frac{M}{\varphi} .
$$

The misallocation in our setting comes exactly from $\Omega_{j} \neq T_{j}$, that is, the difference between the treatment effect and profits from allocating PPP loans to a given firm. In our setting, there are two channels through which profits of the banking sector deviate from the objective

\footnotetext{
${ }^{17}$ For instance, see Peter Rudegeair, “When Their PPP Loans Didn't Come Through These Businesses Broke Up with Their Banks," The Wall Street Journal, July 31, 2020. https://www.wsj.com/articles/when-their-ppploans-didnt-come-through-these-businesses-broke-up-with-their-banks-11596205736.

${ }^{18}$ For instance, on March 31, 2020, the Treasury and the SBA released guidelines for lenders, including one that said banks would need to verify some of the borrowers' information for the loan to be eligible for forgiveness. See Zachary Warmbrodt, "Banks Warn of Chaotic Launch of Small Business Lending Program," Politico, April 2, 2020. https://www.politico.com/news/2020/04/02/banks-small-business-lending-program-launch161106 These guidelines were eventually revised several times, inducing even more uncertainty for lenders.
} 
function of the government. We explore analytically these channels in Lemma 3. First, the banking sector already has a heterogeneous exposure from firms that have outstanding loans and potential future loans to be made to this firm, which is captured by $b_{j}(1-\delta)$. Everything else being equal, this implies that compared with the government, banks allocate loans to firms with more pre-shock debt per worker. ${ }^{19}$ This result is consistent with the empirical findings in the literature. In particular, Bartik et al. (2020b) show that conditional on the set of firms with a relationship with a bank (at the extensive margin), banks approved more loans to firms with higher preexisting debt with those banks at what the authors call a "striking magnitude." In comparison with the results in Lemma 2, this incentive to allocate loans to more indebted firms generates a misallocation whenever $\eta<1$, because when $\eta>1$, it is optimal for the government to allocate PPP loans to firms with the highest pre-pandemic debt levels.

Second, banks are also concerned about the probability of survival of the firms $\Phi_{j}^{\Gamma}(0)$, as those are clients that might switch banks if they don't receive PPP loans or have loans that are not forgiven due to uncertain rules of the program. This implies that, everything else being equal, banks allocate loans to firms with a higher probability of survival without a PPP loan. This incentive can be particularly perverse for the effectiveness of the program, since the firms that do receive loans are exactly those that could survive without the loans. In the second result of Lemma 3, we show that the banking sector distorts the optimal government allocation toward firms with lower $\eta$ 's and thus a higher probability of survival without a PPP loan. We illustrate this second result of Lemma 2 in Figure 3. Intuitively, this result comes from the second term of $\Omega_{j}$ in Eq. (15), that is, the fact that banks also derive larger profits from firms that have a higher probability of survival ex ante. This result is also consistent with the evidence in the empirical literature, which finds that banks accepted more applications from less distressed firms. For instance, Joaquim and Netto (2021) use the Small Business Survey data to show that firms that reported experiencing a revenue decrease in the

\footnotetext{
${ }^{19}$ Note that under the conditions of the first part of Lemma $3, \Omega_{j}$ is strictly increasing in $b_{j}$. However, if we take into account that $b_{j}$ can also enter into the probability of survival without PPP loans, $\Phi_{j}(0)$, we can show that $\Omega_{j}$ is hump shaped in $b_{j}$. This means that compared with the government allocation, banks want to allocate loans to firms with more debt but not necessarily to firms with the highest levels of pre-pandemic debt, as the probability of survival for some of those firms is too small. We opt here for the simpler statement of Lemma 3, as it captures the channels we want to highlight and is consistent with the empirical evidence in Bartik et al. (2020b).
} 
COVID-19 crisis were more likely to apply for, but less likely to receive, a PPP loan in the first round. The effects are quantitatively large. At the NAICS state two-digit level, an increase of 1 percentage point in the share of firms experiencing a revenue decrease is associated with a 0.25 percentage point increase in the gap between PPP application and receipt.

\section{Lemma 3. Banks PPP allocation.}

Debt heterogeneity. Consider that all firms in the economy are the same except for their level of debt $b_{j}$; that is, $c_{j}=c$, and $\eta_{j}=\eta$. The solution to Eq. (16) is such that banks give preference to firms with higher $b_{j}$, that is; $l_{j}^{*, B}=1$ if $b>b^{*, B}$.

Shock exposure heterogeneity. Consider that all firms are the same except for their exposure $\eta_{j}$. The solution to Eq. (16) implies that $\exists ! \underline{\eta}_{B}, \bar{\eta}^{B}$ such that the bank chooses $l_{j}^{*, B}=1$ if $\eta_{j} \in[\underline{\eta}, \bar{\eta}]$ and $l_{j}^{*, B}=0$ otherwise. Additionally, $\underline{\eta}_{B}<\underline{\eta}_{G}$ and $\bar{\eta}_{B}<\bar{\eta}_{G}$; that is, banks distort the allocation toward firms with a higher probability of survival without a PPP loan.

Figure 3: Credit Allocation under the PPP for Firms with Heterogeneous Shock Exposure $\left(\eta_{j}\right)$ : Government (blue, solid) vs. Banks (red, dotted)

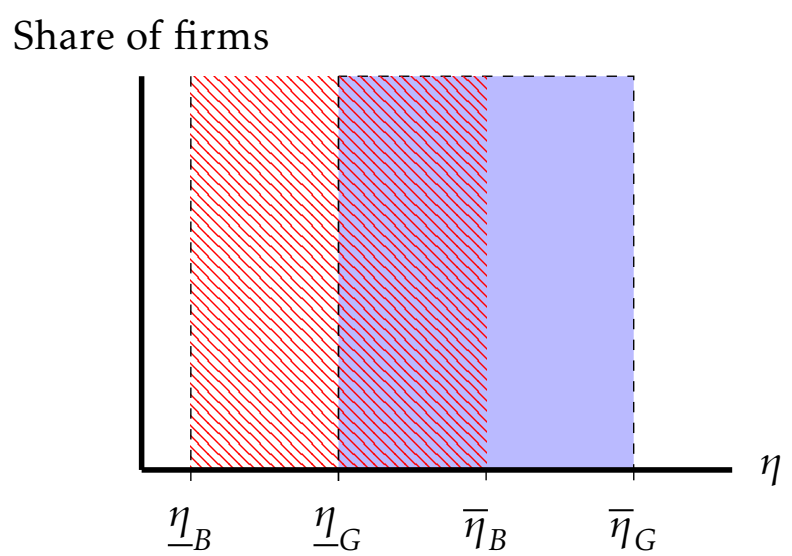

Note: This figure is the pictorial representation of Lemmas 2 and 3. The solid blue rectangle is the government allocation. The dotted red allocation is the banking sector allocation. The $\eta_{G}$ 's are the lower and upper bounds of the regions/sectors for the government, and the $\eta_{B}$ 's are those for the banking sector.

\section{III.5. Asymmetric Information and Capacity Constraints}

In the benchmark version of our model, banks and the government have the same information and same ability to disburse loans. Therefore, there is no reason for the government to intermediate the allocation through the private banking system. We therefore augment our model so that banks have more information and can disperse loans more quickly than 
the government, the reasoning behind the program's use of the banking system (Bartik et al. $(2020 b))$.

First, we introduce differential information between banks and the government. We assume that the government observes the true treatment effect for a share of firms and a random treatment effect for the remaining firms. Importantly, we do not need to say which part of the terms of the treatment effect the government does not observe (that is, if it is the firms' financial position or their probability of survival); instead, we say simply that the government does not observe the true treatment effect, which is a sufficient statistic for the allocation in our setting. Mathematically, let $H(T)$ denote the distribution of treatment effects $T_{j}$ in the population. Suppose that the government observes for every firm $j$ a signal $\hat{T}_{j}$ of the true treatment effect $T_{j}$. The signal is given by $\hat{T}_{j}=T_{j}$ for a share $\mu$ of the population and $\tilde{T}_{j}$ for a share $1-\mu$, where $\tilde{T}_{j}$ is independent of $T_{j}$ but has the same distribution. Note that $\hat{T}_{j}$ and $T_{j}$ have the same distribution, which we denote by $H$.

Second, we introduce the operational capacity distortion. We assume that until the government can create a disbursement system, a share $1-\iota$ of firms will have faced their shocks $v_{j}$ (independently of their signals) such that their treatment effects will be zero; that is, either the firm has already survived with no PPP loans or the firm has not survived.

Let $H_{j \mid s}(j \mid s)$ be the distribution of $T_{j}$ conditional on signal $T_{s}$ (that is, $\hat{T}_{j}=T_{s}$ ). The government now chooses an allocation $l_{s}^{G}$ for each signal $s$. Let the expected average treatment effect of firms with signal $s, T_{s}$, be given by:

$$
E T E_{s} \equiv \int_{j} \iota T_{j} d H_{j \mid s}(j \mid s)
$$

Our information structure implies that $E T E_{s}=(1-\mu) \iota \bar{T}+\mu \iota T_{s}$. Therefore, the problem of the government can be written as:

$$
\max _{\left\{l_{s}^{G}\right\}} \int_{s} T_{s} l_{s}^{G} d H(s) \text { s.t. } \int_{s} l_{s}^{G} d H(s)=\frac{M}{\varphi} .
$$

Note that the problem in Eq. (17) is the same as the problem in Eq. (14). Therefore, the allocation of firms with signal $T_{s}$ is the same as the allocation for type $j$ with treatment effect $T_{j}$ in Lemma 3. Our main result of this section is Lemma 4 . We show that there is a decreasing 
curve in the $\mu-\iota$ space such that if the government has sufficient information (high $\mu$ ) or the delay cost is sufficiently low (high $\iota$ ), then the government prefers to allocate PPP loans itself. In the next section, we use our results from this section to compute the delegation versus misallocation frontier at different moments during the program.

Lemma 4. Delegation versus misallocation: efficiency-information frontier. Let $\iota^{*}(\mu)$ be given by

$$
\iota^{*}(\mu)=\left[(1-\mu) \bar{T}+\mu \int_{\underline{T}}^{\infty} T_{j} d j\right]^{-1} \mathcal{W}_{B},
$$

where $\mathcal{W}_{B} \equiv \int_{j} l_{j}^{*, B} T_{j} d j$ is the welfare from the optimal bank allocation. We have that $(i) \iota^{*}(\mu)$ is decreasing in $\mu$ and (ii) $\forall\{\mu, \iota\}$ s.t. $\iota<\iota^{*}(\mu)$, the government prefers to allocate PPP loans through banks.

\section{EMpirical Application}

In this section, we provide an empirical application of our model. We extend our model to account explicitly for PPP timing and provide the welfare definitions we use throughout this section. Next, we discuss how we recover firm treatment effects from the empirical estimates of the treatment effect $T_{j}$ 's in the PPP from Joaquim and Netto (2021). Finally, we report our results. We compute the misallocation due to the allocation of loans through banks, characterize the efficiency-information frontier from Lemma 4, and consider feasible alternative policies: (i) random allocation of PPP loans across firms and (ii) a policy targeted at the smallest firms.

PPP timing and welfare. So far, our model has focused explicitly on which firms receive PPP loans at a given moment in time. Now, we take into account PPP timing in our welfare computation. For that, we include a discount factor in the welfare function of the government. This discounting is a reduced-form way to capture that, ceteris paribus, the government prefers to allocate loans earlier to firms. For instance, this could capture the channel of Barrot and Nanda (2020), who show that accelerated payments to small businesses increase employment at the firm level. Alternatively, this discounting term captures an overall loss in efficiency from late implementation of the program (our $\iota$ in Section III.5).

Mathematically, let $l_{j, t}=1$ if firm $j$ receives a loan at time $t$. The welfare of the government 
from allocation $l \equiv\left\{l_{j, t}\right\}_{j, t}$ is given by

$$
\mathcal{W}(\boldsymbol{l})=\sum_{t}(1-\xi)^{t} \int_{j} l_{j, t} T_{j} d j,
$$

where $\xi \in(0,1)$ is a discount rate. We calibrate $\xi=.0037$ to match the evidence in Barrot and Nanda (2020) that finds a 5.7 percent increase in employment for a payment of 100 percent of payroll 15 days earlier. This value of $\xi$ implies that a loan allocated to a firm 30 days later is worth approximately 90 percent of a loan allocated today. Our misallocation measure of an allocation $\boldsymbol{l}$ relative to the government optimal allocation $\boldsymbol{l}^{*, G}$ will be given by

$$
\mathcal{M}\left(\boldsymbol{l}, \boldsymbol{l}^{*, G}\right)=\frac{\mathcal{W}(\boldsymbol{l})-\mathcal{W}\left(\boldsymbol{l}^{*, G}\right)}{\mathcal{W}\left(\boldsymbol{l}^{*, G}\right)} .
$$

We interpret $\mathcal{M}\left(\boldsymbol{l}, \boldsymbol{l}^{*, G}\right)$ as a reduction in program effectiveness. For instance, if $\mathcal{M}\left(\boldsymbol{l}, \boldsymbol{l}^{*, G}\right)$, the time-discounted treatment effect relative to the optimal policy, is -0.5 , we interpret this as the PPP being 50 percent less efficient than it could have otherwise been.

Empirical treatment effect. To compute the treatment effect at a given date, we leverage the evidence in Joaquim and Netto (2021). The authors compute the average treatment effect of firms treated until a given time $t$, taking into account the role of banks as intermediaries in the PPP. Joaquim and Netto (2021) show that research designs based on bank or regional shocks in PPP disbursement, commonly found in the empirical literature, yield a misleading interpretation of the effect of the program, and so they propose an alternative estimation method. Intuitively, bank targeting implies that these designs can, at best, recover the effect of the PPP on a set of firms that is endogenous, changes over time, and is systematically different from the overall set of firms that receive PPP loans. The ATT series we use is in Figure A.1. Let $\bar{t}$ denote the end of the first draw of the program (our focus on the paper). For the observed $\widehat{A T T} \equiv\left\{A \hat{T} T_{t}\right\}_{t=1}^{\bar{t}}$ series in Figure A.1, we compute the treatment effect of firms that receive loans exactly at time $t, \hat{T}_{t}$, from

$$
\hat{T}_{0}=\widehat{A T T}_{0} \text { and } A T T_{t}=\bar{w}_{t-1} \hat{T}_{t-1}+w_{t} \hat{T}_{t}, t=1, \ldots, \bar{t}
$$

where $w_{t}$ is the number of employees of firms that receive a loan at time $t$ relative to the total number of employees of firms that receive a PPP loan, and $\bar{w}_{t-1} \equiv \sum_{k=0}^{t-1} w_{k}$. We consider the 
share of employees (and not the number or volume of loans) since the relevant distribution in our setting is the distribution at the job level (Section III.3). Alternatively, we can write Eq. $(21)$ as

$$
\hat{T}_{t} \equiv[\mathcal{P Q}]^{-1} \widehat{A T T}
$$

where $\mathcal{P}$ and $\mathcal{Q}$ are $\bar{t} \times \bar{t}$ matrices with elements in row $r$, column $c$ given by

$$
\mathcal{P}_{r, c}=\left\{\begin{array}{ll}
1, & \text { if } r \geq c \\
0, & \text { if } r<c
\end{array} \text { and } \mathcal{Q}_{r, c}=\left\{\begin{array}{ll}
\frac{w_{c}}{\bar{w}_{r}+w_{r}}, & \text { if } r \geq c \\
0, & \text { if } r<c
\end{array} .\right.\right.
$$

We assume that $\hat{T}_{t}$ is the treatment effect of firms that receive PPP loans at time $t$; that is, there is no within-period treatment effect heterogeneity. This assumption is not necessary for our results, but it slightly changes the interpretation when we discuss the case of asymmetric information between banks and the government. For instance, if we assume that the treatment effect of a firm that receives a loan at $t$ is on average $\hat{T}_{t}$, the interpretation of our asymmetric information exercise is that the government does not observe this average for a share $\mu$ of firms; that is, the government does not observe a noisy measure of the treatment effect.

Counterfactual policies. In our exercise, we consider only a reallocation of PPP funds in terms of timing without changing the total number of jobs supported by the program each day. Two lines of reasoning motivate this approach. First, most of the firms that do not receive PPP loans are those that do not apply for the program (Figure 2), and any program that the government implements will likely also have an application cost. Second, the distribution of firms that receive PPP loans is similar to the overall distribution of US firms from the Census (Figure A.2).

We consider four alternative allocations of funds in the PPP program. First, we consider the observed allocation, which we denote as the bank allocation $\boldsymbol{l}^{*, B}$. Second, we consider the optimal government allocation under the PPP rules, $l^{*, G}$ (Lemma 2). Third, we consider a random allocation of PPP loans across firms, $l^{*, R}$. Finally, we consider the allocation of PPP loans when the government allocates funds to firms following an increasing firm-size order (that is, it starts with the smallest firms), $\boldsymbol{l}^{*, I}$. For a given objective function, we compute $\boldsymbol{l}_{t}^{*}$ at 
the employee level; that is, we consider a reallocation of PPP loans across employees over time, which is the relevant metric in our model. For instance, for the problem of the government at time $t$, we compute $l_{t}^{*, G}$ as

$$
l_{t}^{*, G}=\arg \max _{l_{t, j} \in\{0,1\}} \int_{\mathcal{A}_{t}} l_{t, j} T_{j} d j \text { s.t. } \int_{\mathcal{A}_{t}} l_{t, j} d t=w_{t}
$$

where $\mathcal{A}_{t} \equiv\left\{j \mid j \in \mathcal{A}\right.$ and $\left.\sum_{k-0}^{t-1} l_{t, j}^{*, G}\right\}$ is the set of employees in firms that applied for the PPP and haven't received a loan up to time $t$.

Results. Our results are in Figures 4 and 5 and Table 2. In Panel A of Figure 4, we show the observed versus optimal evolution of average firm size (cumulative) during the PPP. While the observed allocation starts making loans to firms with an average of 30 employees, the optimal allocation focuses on firms with, on average, fewer than five employees. At the end of the first draw of the program, given that there is excess supply of PPP loans, we see that in both cases the average firm size converges to approximately 12 employees. In Panel B of Figure 4, we plot the misallocation under each of our non-optimal allocations: $l^{*, B}$ (banks), $\boldsymbol{l}^{*, R}$ (random), and $\boldsymbol{l}^{*, I}$ (size-based). At the end of the first round (vertical line), the misallocation from allocating funds through banks is large-the program would have been 80 percent less effective. A random allocation of funds or a size-based policy would have reduced this misallocation by, respectively, 50 and 55 percentage points. At the end of the first draw, however, the program would have been only 20 percent less effective compared with the optimal allocation. During the first round, banks targeted firms that were larger and less affected by COVID-19 and thus were far from maximizing the effect of the program. As more funds were appropriated for the PPP in late April, and eventually the supply of PPP loans exceeded demand, the role of banks in the allocation of funds was reduced and the high-treatment-effect firms receive PPP loans. The misallocation as of August 8, 2020, comes from our discount factor, $\xi$; that is, the only misallocation is due to differential timing of PPP loans.

Figure 5 characterizes the efficiency-information frontier from Lemma 4, Eq. (18) on April 16 and May 15, 2020. On April 16, a completely random allocation of funds $\mu=0$ that is only 35 percent as efficient (relative to the banks) in terms of disbursement is preferable to bank intermediation in the program. On May 15, this figure increases to 65 percent. At this point, 
Figure 4: Firm Size and Misallocation

(a) Firm Size

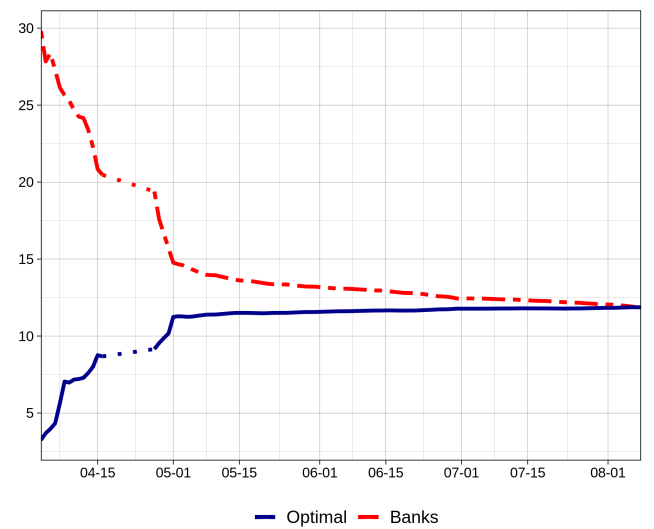

(b) Misallocation

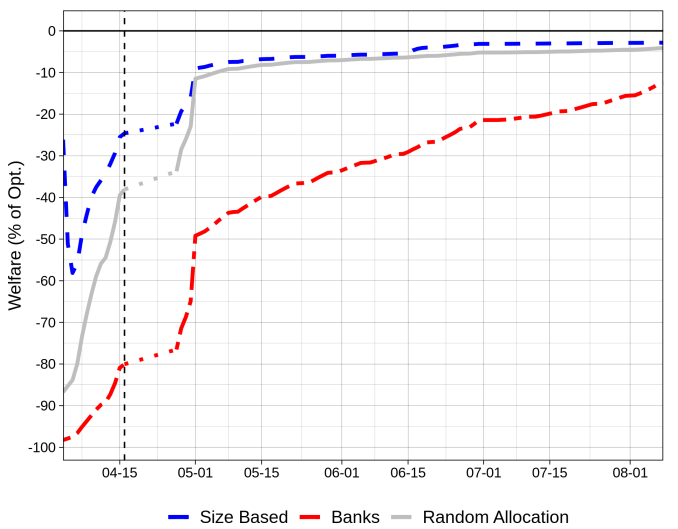

Note: The optimal allocation is computed from the problem in Eq. (24) using the treatment effect from Eq. (22). Panel A. Observed and optimal average firm size (cumulative). Panel B. Misallocation in Eq. (20) under each of our non-optimal allocations: $\boldsymbol{l}^{*, B}$ (banks), $\boldsymbol{l}^{*, R}$ (random), and $\boldsymbol{l}^{*, I}$ (size-based).

most firms have already received loans in the program, and the overall effect of information is relatively muted.

Figure 5: Efficiency-Information Frontier

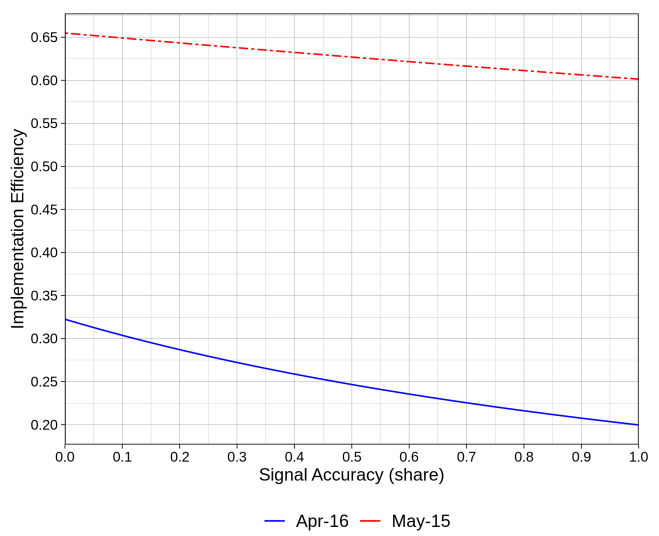

Note: Efficiency-information frontier from Lemma 4, Eq. (18) on April 16 and May 15, 2020. Welfare measures for Eq. (18) come from the use of Eq. (22) in Eq. (19) with the allocation given by Eq. (24) .

\section{IV.1. Optimal Program Size}

So far we have taken the total amount available under the program, $M$, as given. In this section, we discuss the implications of bank incentives for the optimal size of the program. To do so, we suppose that there is an exogenous cost function that fully captures the welfare cost of allocating extra dollars to the program given by $\frac{\vartheta}{2} M^{2}$. The problem of the government 
Table 2: Model Results: Firm Size and Welfare

\begin{tabular}{lccc}
\hline & Apr-16 & May-15 & Aug-08 \\
\hline & \multicolumn{3}{c}{ Optimal Policy } \\
Firm Size $\left(N_{G}\right)$ & 8.68 & 11.51 & 11.87 \\
Program Effect $\left(\mathcal{W}\left(\boldsymbol{l}^{*, G}\right)\right)$ & 0.21 & 0.14 & 0.13 \\
& \multicolumn{3}{c}{ Banks } \\
Firm Size $\left(N_{B}\right)$ & 20.47 & 13.61 & 11.87 \\
Program Effect $\left(\mathcal{W}\left(\boldsymbol{l}^{*, B}\right)\right)$ & 0.04 & 0.08 & 0.11 \\
& \multicolumn{3}{c}{} \\
Random $\left(\mathcal{W}\left(\boldsymbol{l}^{*, R}\right)\right)$ & Effect of Alternative Policies \\
\cline { 2 - 2 } Size-Based $\left(\mathcal{W}\left(\boldsymbol{l}^{*, I}\right)\right)$ & 0.13 & 0.13 & 0.12 \\
\hline \hline
\end{tabular}

Note: The optimal allocation is computed from the problem in Eq. (24) using the treatment effect from Eq. (22). Rows represent: observed $\left(N_{B}\right)$ and optimal $\left(N_{G}\right)$ average firm size (cumulative), welfare in Eq. (19) under each of our optimal allocations: $\boldsymbol{l}^{*, G}$ (government) $\boldsymbol{l}^{*, B}$ (banks), $\boldsymbol{l}^{*, R}$ (random), and $\boldsymbol{l}^{*, I}$ (size-based).

is to choose a program size $M$, subject to either the government or banks allocating the loans, to maximize the government's welfare function

$$
M_{P}^{*} \equiv \arg \max _{M} \int_{\mathcal{A}} l_{j}^{P}(M) T_{j} d j-\frac{\vartheta}{2} M^{2} \text {, where } P \in\{G, B\}
$$

conditional on an allocation $l^{P}(M) \equiv\left\{l_{j}\right\}_{j}$ that satisfies $\int_{\mathcal{A}} l_{j}^{P}(M) d j=\frac{M}{\varphi}$. We analyze the difference between $M_{G}^{*}$ and $M_{B}^{*}$, that is, the optimal program size when loans are allocated through the government and when they are allocated through banks.

The marginal benefit of increasing the program size is given by a share $\varphi^{-1}$ of the treatment effect of the marginal firm receiving a loan. Let $\underline{T}_{G}(M)$ and $\underline{T}_{B}(M)$ denote these firms under the government and bank allocations, respectively. The solution of Eq. (25) is given by ${ }^{20}$

$$
\underline{T}_{G}\left(M_{G}^{*}\right)=\varphi \vartheta M_{G}^{*} \text { and } \underline{T}_{B}\left(M_{B}^{*}\right)=\varphi \vartheta M_{B}^{*}
$$

We plot the difference $\Delta_{T} \equiv \underline{T}_{B}-\underline{T}_{G}$ implied by the data in Figure 6. We focus the analysis

\footnotetext{
${ }^{20}$ Here we assume implicitly that the first-order condition of Eq. (25) in Eq. (26) is sufficient to characterize the global optimum. This assumption is true for the problem of the government, given that $\underline{T}_{G}(0)>0, \underline{T}_{G}(M)$ is strictly decreasing in $M$ and $\vartheta M$ is strictly increasing in $M$. For the problem of the bank, we are implicitly assuming here that $\underline{T}_{B}(0)>0$, that is, that the bank does not choose a firm with a zero treatment effect (in case a firm with zero treatment effect exists), and that it crosses the marginal cost curve $\vartheta M$ once and from above. This assumption is satisfied, for instance, if $\underline{T}_{B}(M)$ is increasing or concave. Both of these conditions are satisfied in our empirical application.
} 
of optimal program size until May 2020 (instead of August 2020), since after this point the program is large enough that there is no excess demand for PPP loans. In the first round of the program, $\Delta_{T}$ is negative: Banks are allocating loans, at the margin, to firms with lower treatment effects relative to the government allocation. This difference flips at the end of the first round, and by the second round banks, relative to the government, are allocating loans to firms with higher treatment effects (since the government already allocated PPP loans for high-treatment-effect firms early in the program).

Figure 6: Treatment Effect Difference at the Marginal Firm

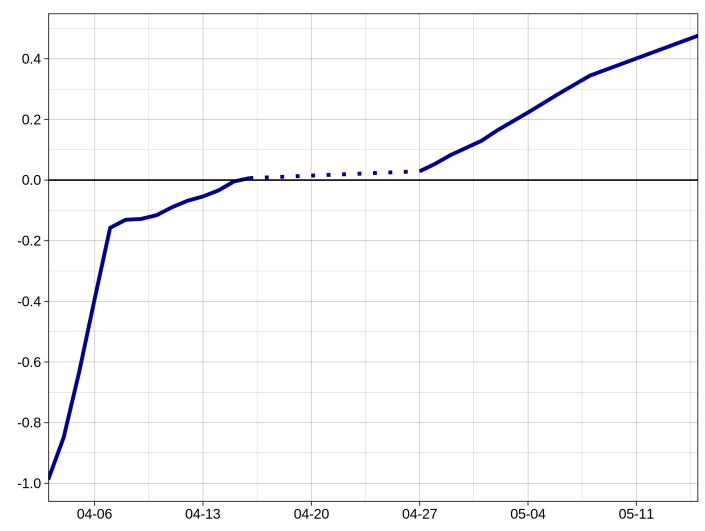

Note: Difference in implied treatment effects of firms receiving PPP loans at a given date, $\Delta_{T} \equiv \underline{T}_{B}-\underline{T}_{G}$.

Combining Eq. (26) with our evidence in Figure 6, we can arrive at the following result: If the marginal cost of raising funds is high (high $\vartheta$ ), such that the optimal program size when banks allocate loans is small (for instance, smaller than the first round of the PPP), we have that $M_{G}^{*}>M_{B}^{*}$. At $M_{B}^{*}$, the marginal firm entering the program through the government allocation has a higher treatment effect than the marginal firm entering the program due to bank allocation, and thus $\underline{T}_{G}\left(M_{B}^{*}\right)>\underline{T}_{B}\left(M_{B}^{*}\right)=\varphi \vartheta M_{B}^{*}$. The opposite is true if the cost of the marginal dollar in the program is low (low $\vartheta$ ). Intuitively, we have two competing forces in establishing the optimal size of the program when banks allocate loans. On the one hand, we have that funds are costly. On the other hand, as the program grows, the propensity for banks to misallocate loans toward firms with low treatment effects is reduced. Our analysis shows that if the marginal cost is high, the former dominates, while if the marginal cost is low, the latter dominates. 


\section{Conclusion}

As a response to the COVID-19 crisis, the US government created the PPP to preserve jobs in small and medium-sized businesses. In 2020 and 2021, the PPP disbursed $\$ 800$ billion in loans and grants to small businesses. To guarantee a timely delivery of loans to businesses, the program was intermediated by banks. The empirical literature shows that PPP loans were allocated earlier to firms that were larger and had more pre-pandemic debt and to firms that would have had a higher probability of survival without PPP loans (including those less affected by the pandemic). In this paper, we focus on three questions. First, what should the optimal allocation of PPP loans have been from the perspective of the government? Second, what distortions were caused by the allocation of these loans through the banking system? Third, are there any alternative policies that could have been implemented to minimize the misallocation of PPP loans?

To answer these questions, we develop a theoretical framework of the PPP. Our framework features firms, banks, and the government. Each firm faces a random cost shock as a result of the COVID-19 crisis. Firms choose to apply for the PPP and, conditional on applying, the total amount they apply for in the program is limited to a multiple of their total payroll. Consistent with the stated program objectives, we assume that the government wants to maximize the number of preserved jobs. In terms of the optimal allocation of PPP loans, we find that the government should allocate PPP loans to firms whose treatment effects are the highest. In our model, these firms are those that are likely to be intermediately affected by the pandemic. Firms that are expected to be severely affected by the pandemic will likely shut down, while firms not significantly affected by the shock will likely survive-regardless of the allocation of PPP loans. In our model, banks have an incentive to distort the allocation toward firms that would have been more likely to survive without a PPP loan, which is consistent with the empirical evidence.

We provide an empirical application of our model. We find that if the program had only one round (and had allocated "only" \$ 349 billion), the misallocation would have been quantitatively large. Given that the program was subsequently enlarged and there was an excess supply of PPP loans at the end of our sample, we find that the misallocation was relatively small when we take into account all loans made through the first draw of the program. From 
a policy design perspective, our paper provides a theoretical framework for emergency lending programs that are now part of the crisis-response toolkit. Our model provides guidance as to which firms should be targeted by the government, indicates under which conditions the program should be intermediated by the banking system versus implemented directly by the government, and studies the optimal program size. 


\section{REFERENCES}

Amiram, Dan, and Daniel Rabetti. 2020. “The Relevance of Relationship Lending in Times of Crisis." SSRN Working Paper. 4, 6

Autor, David, David Cho, Leland D Crane, Byron Lutz, Joshua Montes, William B Peterman, David Ratner, Daniel Villar, and Ahu Yildirmaz. 2020. “An Evaluation of the Paycheck Protection Program Using Administrative Payroll Microdata.” 5, 9

Bachas, Natalie, Olivia S. Kim, and Constantine Yannelis. 2020. "Loan Guarantees and Credit Supply." Journal of Financial Economics. 6

Barrios, John Manuel, Michael Minnis, William C. Minnis, and Joost Sijthoff. 2020. "Assessing the Payroll Protection Program: A Framework and Preliminary Results." SSRN Electronic Journal. 6

Barrot, Jean-noël, and Ramana Nanda. 2020. "The employment effects of faster payment: evidence from the federal quickpay reform." The Journal of Finance, 75(6): 3139-3173. 25, 26

Bartik, Alexander W., Marianne Bertrand, Zoe Cullen, Edward L. Glaeser, Michael Luca, and Christopher Stanton. 2020a. "The impact of COVID-19 on small business outcomes and expectations." 2, 12

Bartik, Alexander W., Zoe E. Cullen, Edward L. Glaeser, Michael Luca, Christopher T. Stanton, and Adi Sunderam. 2020b. "The Targeting and Impact of Paycheck Protection Program Loans to Small Businesses.” NBER Working Paper No. 27623. 2, 3, 4, 6, 16, 22, 24

Bartlett, Robert P, and Adair Morse. 2020. "Small Business Survival Capabilities and Policy Effectiveness: Evidence from Oakland." 5, 19

Beck, Thorsten, Leora F Klapper, and Juan Carlos Mendoza. 2010. “The Typology of Partial Credit Guarantee funds around the World." Journal of Financial Stability, 6(1): 10-25. 5, 6

Brown, J David, and John S Earle. 2017. "Finance and Growth at the Firm Level: Evidence from SBA Loans.” The Journal of Finance, 72(3): 1039-1080. 6 
Buffington, Catherine, Carrie Dennis, Emin Dinlersoz, Lucia Foster, Shawn Klimek, et al. 2020. "Measuring the Effect of COVID-19 on US Small Businesses: The Small Business Pulse Survey." 10

Chetty, Raj, John N Friedman, Nathaniel Hendren, Michael Stepner, and Opportunity Insights Team. 2020. “The Economic Impacts of COVID-19: Evidence from a New Public Database Built from Private Sector Data." 2, 5

Chodorow-Reich, Gabriel, Olivier Darmouni, Stephan Luck, and Matthew Plosser. 2020. "Bank Liquidity Provision Across the Firm Size Distribution." National Bureau of Economic Research, Cambridge, MA. 5

Core, Fabrizio, and Filippo De Marco. 2021. "Public guarantees for small businesses in italy during covid-19." 5

Cororaton, Anna, and Samuel Rosen. 2020. "Public Firm Borrowers of the US Paycheck Protection Program." SSRN Electronic Journal. 6

Davis, Steven J, and Till M Von Wachter. 2011. "Recessions and the cost of job loss." National Bureau of Economic Research. 7

de Blasio, Guido, Stefania De Mitri, Alessio D’Ignazio, Paolo Finaldi Russo, and Lavinia Stoppani. 2018. "Public Guarantees to SME Borrowing. A RDD Evaluation." Journal of Banking E Finance, 96: 73-86. 6

Doniger, Cynthia, and Benjamin Kay. 2020. “Ten Days Late and Billions of Dollars Short: The Employment Effects of Delays in Paycheck Protection Program Financing." Available at SSRN. 2, 5, 14

Elenev, Vadim, Tim Landvoigt, and Stijn Van Nieuwerburgh. 2020. "Can the Covid Bailouts Save the Economy?” NBER Working Paper 27207, Cambridge, MA. 6

Erel, Isil, and Jack Liebersohn. 2020. "Does FinTech Substitute for Banks? Evidence from the Paycheck Protection Program.” NBER Working Paper 27659, Cambridge, MA. 5

Faria-e Castro, Miguel. 2020. “Fiscal Policy during a Pandemic.” NBER Working Paper. 6 
Gale, William G. 1990. "Federal Lending and the Market for Credit.” Journal of Public Economics, 42(2): 177-193. 6

Gale, William G. 1991. "Economic Effects of Federal Credit Programs." The American Economic Review, 133-152. 6

Gonzalez-Uribe, Juanita, and Su Wang. 2019. "Dissecting the Effect of Financial Constraints on Small Firms.” Working Paper. 6

Granja, João, Christos Makridis, Constantine Yannelis, and Eric Zwick. 2020. "Did the Paycheck Protection Program Hit the Target?" 2, 5, 6, 17

Guerrieri, Veronica, Guido Lorenzoni, Ludwig Straub, and Iván Werning. 2020. “Macroeconomic Implications of COVID-19: Can Negative Supply Shocks Cause Demand Shortages?” National Bureau of Economic Research, Cambridge, MA. 2, 11, 12

Hassan, Tarek Alexander, Stephan Hollander, Laurence van Lent, Markus Schwedeler, and Ahmed Tahoun. 2020. "Firm-level Exposure to Epidemic Diseases: Covid-19, SARS, and H1N1." NBER Working Paper 26971, Cambridge, MA. 6

Joaquim, Gustavo, and Felipe Netto. 2021. "The Optimal Allocation of Relief Funds: The Case of the Paycheck Protection Program." Federal Reserve Bank of Boston Research Department Working Paper. 2, 4, 5, 6, 7, 11, 20, 22, 25, 26, A-1

Julien, Jean-Noël Barrot Thorsten Martin, and Sauvagnat Boris Vallée. 2020. "Employment Effects of Alleviating Financing Frictions: Worker-level Evidence from a Loan Guarantee Program." 6

Lelarge, Claire, David Sraer, and David Thesmar. 2010. "Entrepreneurship and Credit Constraints: Evidence from a French Loan Guarantee Program." International Differences in Entrepreneurship, 243-273. University of Chicago Press. 6

Li, Lei, and Philip Strahan. 2020. "Who Supplies PPP Loans (And Does It Matter)? Banks, Relationships and the Covid Crisis." NBER Working Paper 28286. 4, 6

Mullins, William, and Patricio Toro. 2016. "Credit Guarantees and Credit Constraints." Working Paper. 6 
Neilson, Christopher, John Eric Humphries, and Gabriel Ulyssea. 2020. "Information Frictions and Access to the Paycheck Protection Program." NBER Working Paper 27624, Cambridge, MA. 3, 5, 13 


\section{Appendix}

\section{A. Additional Figures and Tables}

Figure A.1: Empirical Estimate of the Treatment Effect

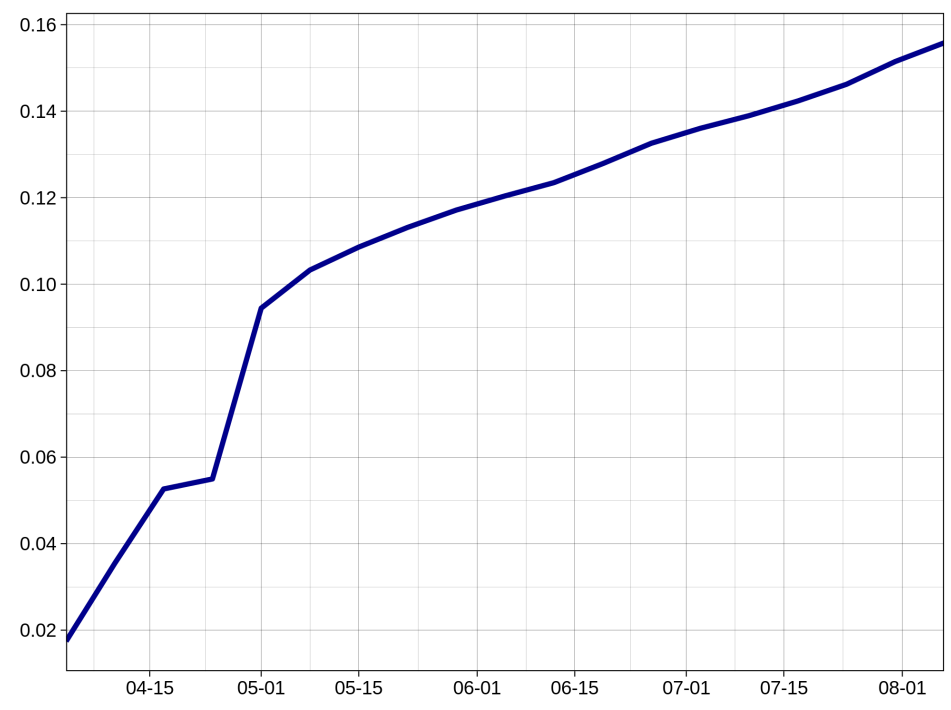

Note: Lower bound of the treatment effect on the treated in the PPP from Joaquim and Netto (2021).

Figure A.2: Share of Total Employment by Firm Size: PPP Microdata and Census

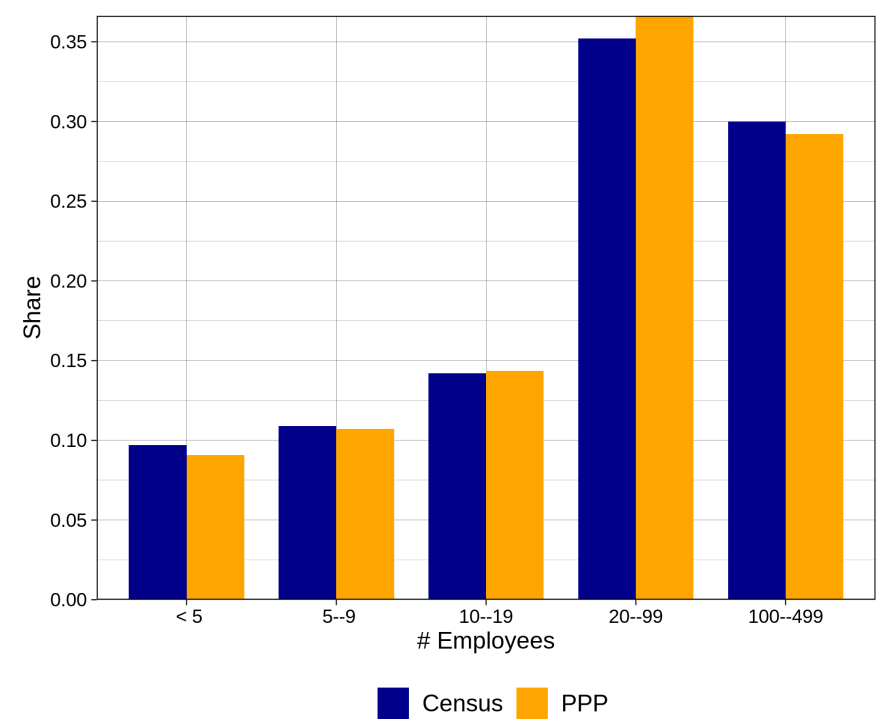

Note: Data from the SBA/Treasury PPP release and US Census (2017). For details on SBA/Treasury data, see Figure 1. Share of total employment from firms in each bin. 


\section{B. Proofs and Derivations}

\section{B.1. Firm's Choice in the PPP}

Auxiliary result. For the distribution in Eq. (3), we have that $\mathbb{E}[v \mid v \leq X]=\frac{\eta}{\eta+1} X$

$$
\mathbb{E}[v \mid v \leq X]=\left(\frac{X}{c_{0}}\right)^{-\eta} \int_{0}^{X} \eta t \frac{1}{c_{0}}\left(\frac{t}{c_{0}}\right)^{\eta-1} d t=(X)^{-\eta} \eta \int_{0}^{X} t^{\eta} d t=X^{-\eta} \eta \frac{X^{\eta+1}}{\eta+1}=\frac{\eta}{\eta+1} X
$$

We proceed in two steps. First, we consider the case where $a=1$ (firm applies), and then compute the amount of funds in the application, $\omega$. Then, we focus on which firms choose to apply.

Step 1: Choice of $\omega$ given $a=1$. From the problem of the firm in Eq. (2), we can take the FOC w.r.t. $\omega$ when $a=1$ to obtain

$$
\phi_{j}(\omega) \cdot\left[\Pi_{j}(\omega)-\frac{\eta_{j}}{\eta_{j}+1} \Gamma_{j}(\omega)\right]-\Phi_{j}(\omega) \cdot r_{G}>0
$$

from $\Phi_{j}(\omega) \geq 0$ and $\Pi_{j}(\omega)>\Gamma_{j}(\omega)>\frac{\eta_{j}}{\eta_{j}+1} \Gamma_{j}(\omega)$.

Step 2: Choice of $a$. From the firm objective function in Eq. (4), a firm chooses to apply if

$$
\Phi_{j}(\varphi)\left(\Pi_{j}(\varphi)-\mathbb{E}\left[v_{j} \mid v_{j} \leq \Gamma_{j}(\varphi)\right]\right)-\Phi_{j}(0)\left(\Pi_{j}(0)-\mathbb{E}\left[v_{j} \mid v_{j} \leq \Gamma_{j}(0)\right]\right)>\frac{F}{N_{j}}
$$

Therefore, $a_{j}^{*}=1$ if :

$$
T_{j} \Pi_{j}(0)-\Phi_{j}(\varphi) r_{G} \varphi-\int_{\Gamma_{j}(0)}^{\Gamma_{j}(\varphi)} v d \Phi\left(v \mid \eta_{j}\right)>\frac{F}{N_{j}}
$$

which delivers Eq. (6). Using the distribution in Eq. (3):

$$
T_{j} \Pi_{j}(0)-T_{j} \mathbb{E}\left[v_{j} \mid v_{j} \in\left[\Gamma_{j}(0), \Gamma_{j}(\varphi)\right]\right]=\left(c_{j}+\pi_{j}^{L R}\right) T_{j}-\Phi_{j}(\varphi) \frac{\eta_{j}}{\eta_{j}+1}\left(c_{j}+\varphi\right)+\Phi_{j}(0) \frac{\eta_{j}}{\eta_{j}+1} c_{j},
$$

which delivers Eq. (7). 


\section{B.2. Lemma 1}

Proof. Let $\lambda$ be the Lagrange multiplier on the constraint that $\int N_{j} \omega_{j}^{G} d j=M$. Taking the FOC of Eq. (9) w.r.t. $\omega_{j}^{G}$

$$
N_{j} \phi\left[\Gamma\left(\omega_{j}^{G}\right)\right] \cdot \frac{\partial \Gamma_{j}}{\partial \omega_{j}^{G}}-N_{i} \lambda=0 \Rightarrow \phi\left[\Gamma\left(\omega_{i}^{G}\right)\right]=\phi\left[\Gamma\left(\omega_{j}^{G}\right)\right], \forall i, j,
$$

where we use that $\frac{\partial \Gamma_{j}}{\partial \omega_{j}^{G}}=1$ of the last equation. Let $\tilde{\lambda} \equiv \lambda \cdot c_{0}^{\eta}$. Using the equation for the distribution $\phi(v)$ in Eq. (3):

$$
\eta_{j}\left[c_{j}+\omega_{j}^{G, *}\right]^{\eta-1}-\tilde{\lambda}=0 \Rightarrow \omega_{j}^{G, *}=\left(\frac{\tilde{\lambda}}{\eta_{j}}\right)^{\frac{1}{\eta_{j}-1}}-c_{j} \Rightarrow M+\bar{c}=\int N_{j}\left(\frac{\tilde{\lambda}}{\eta_{j}}\right)^{\frac{1}{\eta_{j}-1}} d j,
$$

where the last equality comes from integrating $N_{j} \omega_{j}^{G, *}$ across firms to solve for $\lambda$. This is the unique global maximum of the problem, as the constraint is linear and the objective function is strictly concave.

Note that the RHS is (i) strictly decreasing in $\tilde{\lambda}$ since $\eta_{j}<1$, (ii) goes to infinity with $\tilde{\lambda} \rightarrow 0$, and (iii) goes to zero with $\tilde{\lambda} \rightarrow \infty$, so there is always a unique solution for $\tilde{\lambda}$ from Eq. (28). We can use Eq. (28) in the individual firm $j$ equation to obtain:

$$
N_{j} \omega_{j}^{G, *}=M-\left[N_{j} c_{j}-\bar{c}\right]+N_{j}\left(\frac{\tilde{\lambda}}{\eta_{j}}\right)^{\frac{1}{\eta_{j}-1}}-\int N_{j}\left(\frac{\tilde{\lambda}}{\eta_{j}}\right)^{\frac{1}{\eta_{j}-1}} d j
$$

Thus, we have that $N_{j} \tau\left(\eta_{j}, \bar{M}\right) \equiv N_{j}\left(\frac{\tilde{\lambda}}{\eta_{j}}\right)^{\frac{1}{\eta_{j}-1}}-\int N_{j}\left(\frac{\tilde{\lambda}}{\eta_{j}}\right)^{\frac{1}{\eta_{j}-1}} d j$. Therefore:

$$
\frac{\partial \omega_{j}^{G, *}}{\partial \eta_{j}}=\frac{\partial \tau\left(\eta_{j}, \bar{M}\right)}{\partial \eta_{j}}=-\left(\frac{\tilde{\lambda}}{\eta_{j}}\right)^{\frac{1}{\eta_{j}-1}} \frac{1}{\left(\eta_{j}-1\right)^{2}}\left[\ln (\tilde{\lambda})+1-\frac{1}{\eta_{j}}-\ln \left(\eta_{j}\right)\right]
$$

Let $f(\eta)=1-\eta^{-1}-\ln (\eta)$. We know that $f(1)=0$ and $f^{\prime}(\eta)=\eta^{-2}-\eta^{-1}$. Thus, $f(\eta)<0$ for $\eta<1$.

Case 1. If $\tilde{\lambda}<1$, we have that $\frac{\partial \omega_{i, j}^{G, *}}{\partial \eta_{j}}>0$. To see this, note that $f\left(\eta_{j}\right)<0$ and $\ln (\tilde{\lambda})<0$, thus in Eq. (30) the RHS is positive. For $\tilde{\lambda}<1$, we need $M+\bar{c}>\int N_{j}\left(\eta_{j}\right)^{\frac{1}{1-\eta_{j}}} d j$. 
Case 2. if $\tilde{\lambda}>1$, we have that $\frac{\partial \tau\left(\eta_{j}, \bar{M}\right)}{\partial \eta_{j}}$ is positive for $\eta_{j}<\bar{\eta}<1$ and negative otherwise (that is, the transfer function $\tau$ is concave in $\left.\eta_{j}\right)$. To see this, note that $\lim _{\eta \rightarrow 0^{+}} f(\eta)+\ln (\tilde{\lambda})=-\infty$, $f(1)+\ln (\tilde{\lambda})>0$ and $f(\eta)+\ln (\tilde{\lambda})$ always increasing. Therefore, by the intermediate value theorem, we have that $\exists ! \bar{\eta}<1$ s.t. $\frac{\partial \tau\left(\eta_{j}, \bar{M}\right)}{\partial \eta_{j}}>0 \Leftrightarrow \eta_{j}<\bar{\eta}$. For $\tilde{\lambda}>1$, we need $M+\bar{c}<$ $\int N_{j}\left(\eta_{j}\right)^{\frac{1}{1-\eta_{j}}} d j$.

\section{B.3. Lemma 2}

Proof. Let $G\left(\left\{l_{j}^{G}\right\}_{j}\right)$ be the Lagrangian of the problem of the government in Eq. (12). The derivative of the Lagrangian $G($.$) with respect to l_{j}^{G}$, that is, the marginal allocation

$$
G_{l} \equiv \frac{\partial G}{\partial l_{j}^{G}}=T_{j}-\varphi \lambda,
$$

where $\lambda$ is the Lagrange multiplier in the resource constraint.

Case 1. Debt heterogeneity. Consider that all firms in the economy are the same except for their level of debt $b_{j}$. Then:

$$
T_{j}=c_{0}^{-\eta}\left[\rho-b_{j}+\varphi\right]^{\eta}-c_{0}^{-\eta}\left[\rho-b_{j}\right]^{\eta} \Rightarrow \frac{\partial T_{j}}{\partial b_{j}}=-c_{0}^{-\eta} \eta\left(\left[\rho-b_{j}+\varphi\right]^{\eta-1}-\left[\rho-b_{j}\right]^{\eta-1}\right) .
$$

For $\eta<1, T_{j}$ is thus increasing in $b_{j}$. For $\eta>1, T_{j}$ is decreasing in $b_{j}$.

Case 2. Shock exposure Heterogeneity. Consider that all firms are the same except for their shock exposure $\eta_{j}$. Define $\tilde{c} \equiv \frac{c}{c_{0}}$ and $\tilde{\varphi} \equiv \frac{\varphi}{c_{0}}$. Then:

$$
\frac{\partial T_{j}}{\partial \eta_{j}}=(\tilde{c}+\tilde{\varphi})^{\eta_{j}} \cdot \ln (\tilde{c}+\tilde{\varphi})-\tilde{c}^{\eta_{j}} \ln (\tilde{c})>0 \Leftrightarrow(\tilde{c}+\tilde{\varphi})^{\eta_{j}} \cdot \ln (\tilde{c}+\tilde{\varphi})>\tilde{c}^{\eta_{j}} \ln (\tilde{c})
$$

Which implies:

$$
\eta_{j} \ln \left(1+\frac{\varphi}{c}\right)+\ln (-\ln (\tilde{c}+\tilde{\varphi}))<\ln (-\ln (\tilde{c})) \Leftrightarrow \eta_{j}<\eta_{G}^{*} \equiv \frac{\ln \left(\frac{\ln (\tilde{c})}{\ln (\tilde{c}+\tilde{\varphi})}\right)}{\ln \left(1+\frac{\varphi}{c}\right)}>0 .
$$

Therefore, $T_{j}$ is strictly increasing up to $\eta_{G}^{*}>0$ and strictly decreasing afterward. The optimal allocation is thus $l_{j}^{G}=1$ if $\eta_{j} \in\left[\underline{\eta}_{G}, \bar{\eta}^{G}\right]$, where $T_{\underline{\eta}}=T_{\bar{\eta}}$ and $\int_{\underline{\eta}_{G}}^{\bar{\eta}^{G}} \varphi d j=M$, which (i) exists, since 
the resource constraint is binding and (ii) is unique, since $T_{j}$ is quasi-concave in $\eta_{j}$.

\section{B.4. Lemma 3}

Proof. We will proceed as in the proof of Lemma 2. Let $B\left(\left\{l_{j}^{B}\right\}_{j}\right)$ be the Lagrangian of the problem of the government in Eq. (12). The derivative of the Lagrangian of $B($.$) with respect$ to $l_{j}^{B}$, that is, the marginal allocation

$$
B_{l} \equiv \frac{\partial B}{\partial l_{j}^{B}}=\Omega_{j}-\varphi \lambda
$$

where $\lambda$ is the Lagrange multiplier in the resource constraint.

Case 1. Debt heterogeneity. When firms are heterogeneous only in $b_{j}$, we have $\frac{\partial \Omega_{j}}{\partial b_{j}}=T_{j}(1-$ $\delta)\left(1+\psi_{F}\right)+\theta_{j} \psi_{C} \psi_{F} b_{j}>0$; that is, banks want to allocate loans to the firms with the highest levels of pre-pandemic debt per worker.

Case 2. Shock exposure heterogeneity. Consider that all firms are the same except $\eta_{j}$. Then:

$$
\frac{\partial \Omega_{j}}{\partial \eta_{j}}=\left[\kappa(\tilde{c}+\tilde{\varphi})^{\eta_{j}} \cdot \ln (\tilde{c}+\tilde{\varphi})-(\kappa-\tilde{\psi}) \tilde{c}^{\eta_{j}} \ln (\tilde{c})\right]
$$

where $\kappa \equiv(1-\delta) b+\psi_{F}+q \varphi$ and $\tilde{\psi} \equiv \psi_{F} \psi_{C}+q \varphi$. Therefore

$$
\frac{\partial \Omega_{j}}{\partial \eta_{j}}>0 \Leftrightarrow(c+\tilde{\varphi})^{\eta_{j}} \cdot \ln (\tilde{c}+\tilde{\varphi})>\left[1-\frac{\tilde{\psi}}{\kappa}\right] \tilde{c}^{\eta_{j}} \ln (\tilde{c})
$$

Which implies:

$$
\eta_{j} \ln \left(1+\frac{\varphi}{c}\right)+\ln (-\ln (\tilde{c}+\tilde{\varphi}))<\ln \left(-\left[1-\frac{\tilde{\psi}}{\mathcal{K}}\right] \ln (c)\right) \Leftrightarrow \eta_{j}<\eta_{B}^{*} \equiv \frac{\ln \left(\left[1-\frac{\tilde{\psi}}{\mathcal{\kappa}}\right] \frac{\ln (\tilde{c})}{\ln (\tilde{c}+\tilde{\varphi})}\right)}{\ln \left(1+\frac{\varphi}{c}\right)}
$$

since $\tilde{\psi}<\kappa$.

Therefore, $B_{j}$ is strictly increasing up to $\eta_{B}^{*}>0$ and strictly decreasing afterward. The optimal allocation is thus $l_{j}^{B}=1$ if $\eta_{j} \in\left[\underline{\eta}^{B}, \bar{\eta}^{B}\right]$, where $B_{\underline{\eta}_{j}^{B}}=B_{\bar{\eta}_{j}^{B}}$ and $\int_{\underline{\eta}_{B}}^{\bar{\eta}_{B}} \varphi d j=M$, which (i) exists, since the resource constraint is binding and (ii) is unique, since $B_{j}$ is quasi-concave.

Finally, we will show that: $\bar{\eta}_{B}<\bar{\eta}_{G}$ and $\underline{\eta}_{B}<\underline{\eta}_{G}$. By contradiction, assume that $\bar{\eta}_{B} \geq \bar{\eta}_{G}$. 
In this case, $\bar{\eta}_{B} \geq \bar{\eta}_{G}$ (from the resource constraint). The strategy of the proof is to take an alternative $\eta$ smaller but sufficiently close to $\underline{\eta}_{G}$ and show that the profit at this point is higher than at $\bar{\eta}_{G}$. The $T_{j}$ at this point will be closer to a point at $\bar{\eta}^{G}$, but the probability of survival will be much higher, and thus this point will offer a much higher profit for the bank. Mathematically, given that $T_{\eta}$ is a continuous function at $\eta>0$, we have that $\forall \varepsilon>0, \exists \zeta>0$

$$
\left|\eta-\underline{\eta}_{G}\right|<\zeta \Rightarrow\left|T_{\eta}-T_{\underline{\eta}_{G}}\right|<\varepsilon
$$

Take $\varepsilon<\kappa^{-1} \tilde{\psi}\left[\Phi_{\underline{\eta}_{G}}(0)-\Phi_{\bar{\eta}_{G}}(0)\right]$. Then, there $\exists \eta=\underline{\eta}_{G}-\zeta$, with $\zeta>0$ such that:

$$
\kappa T_{\bar{\eta}_{G}}+\tilde{\psi} \Phi_{\bar{\eta}_{G}}(0)=\kappa T_{\underline{\eta}_{G}}+\tilde{\psi} \Phi_{\bar{\eta}_{G}}(0)<\kappa T_{\eta}+\tilde{\psi} \Phi_{\underline{\eta}_{G}}(0)<\kappa T_{\eta}+\tilde{\psi} \Phi_{\eta}(0)
$$

Therefore, $\bar{\eta}_{B} \geq \bar{\eta}_{G}$ cannot be optimal for the bank.

\section{B.5. Lemma 4}

Proof. Let $\mathcal{W}_{G}(\mu, \iota)$ be the social welfare under the government allocation (the same as in Lemma 2) and $\mathcal{W}_{B}$ the social welfare under the optimal bank allocation (the same as in Lemma 2). We know that $\mathcal{W}_{G}$ is differentiable and strictly increasing in both arguments, since:

$$
\mathcal{W}_{G}(\mu, \iota)=(1-\mu) \iota \bar{T}+\mu \iota \int_{\underline{T}}^{\infty} T_{j} d j,
$$

where $\underline{T}$ is the minimum value of the treatment effect that receives PPP loans; that is, $\int_{\underline{T}}^{\infty} d j=$ $\frac{M}{\varphi}$. In Lemma 2, for instance, this corresponds to the treatment effect at the border of the interval $\left[\underline{\eta}_{G}, \bar{\eta}_{G}\right]$. Moreover, for any alternative allocation with welfare $\mathcal{W}_{B}$, let

$$
\iota^{*}(\mu)=\frac{\mathcal{W}_{B}}{(1-\mu) \bar{T}+\mu \int_{\underline{T}}^{\infty} T_{j} d j},
$$

which is strictly decreasing in $\mu$. Moreover, we have that $\iota<\iota^{*}(\mu) \Leftrightarrow \mathcal{W}_{B}>\mathcal{W}_{G}(\mu, \iota)$. 


\section{Constrained First-Best: Extensions}

\section{C.1. Example of Constrained First-Best with $\eta_{j}>1$.}

Suppose that there are two equally present types of firms in the economy, $H$ and $L$. All firms have zero pre-pandemic profits $\pi_{j}=0$. However, each firm has its own $\eta_{F}, F \in\{L, H\}$, with $\eta_{H}>\eta_{L}$. Let the total amount of the program be $M=1$. The constrained first-best (CFB) in this case:

$$
\max _{d \in[0,1]} d^{\eta_{H}}+(1-d)^{\eta_{L}}
$$

For $\eta_{H}>\eta_{L}>1$, this function is maximized with $d=0$ or $d=1$. The government in this case is indifferent to the choice between allocating loans to the most or least affected firms.

\section{C.2. Super and Submodular Distributions.}

Let $v_{j} \sim \Upsilon\left(\pi_{j}+\omega_{j}, \theta_{j}\right)$, where $\theta_{j} \in \Theta$, a complete lattice, parameterizes the distribution $\Upsilon$ and can be different across firms and that, as in the text, a higher $\theta$ implies that a firm is more affected in a FOSD. Take $j, \hat{j}$ such that $\theta>\hat{\theta}$. Let $\omega^{*}, \hat{\omega}^{*}$ be candidates for an optimum for these two types.

Suppose by contradiction that for $\omega^{*} \leq \hat{\omega}^{*}$. For the strict inequality, since $\Upsilon$ is strictly supermodular

$$
\Upsilon\left(\hat{\omega}^{*}, \theta\right)-\Upsilon\left(\omega^{*}, \theta\right)>\Upsilon\left(\hat{\omega}^{*}, \hat{\theta}\right)-\Upsilon\left(\omega^{*}, \hat{\theta}\right) \Leftrightarrow \Upsilon\left(\omega^{*}, \theta\right)+\Upsilon\left(\hat{\omega}^{*}, \hat{\theta}\right)<\Upsilon\left(\hat{\omega}^{*}, \theta\right)+\Upsilon\left(\omega^{*}, \hat{\theta}\right)
$$

For the case where $\omega^{*}=\hat{\omega}^{*}, \forall \varepsilon>0$ : $\Upsilon\left(\omega^{*}-\varepsilon, \theta\right)+\Upsilon\left(\omega^{*}+\varepsilon, \hat{\theta}\right)<\Upsilon\left(\omega^{*}+\varepsilon, \theta\right)+\Upsilon\left(\omega^{*}-\varepsilon, \hat{\theta}\right)$. The same argument applies for the submodular case. 